\title{
Prosodic influences on consonant production in Dutch: Effects of prosodic boundaries, phrasal accent and lexical stress
}

\author{
Taehong Cho ${ }^{\mathrm{a}, *}$, James M. McQueen ${ }^{\mathrm{b}}$ \\ ${ }^{a}$ Division of English Language and Literature, Hanyang University, 17 Haengdang-dong, Seongdong-gu, \\ Seoul 133-791, Korea \\ ${ }^{\mathrm{b}}$ Max Planck Institute for Psycholinguistics, Nijmegen, The Netherlands
}

Received 30 July 2003; received in revised form 13 December 2004; accepted 12 January 2005

\begin{abstract}
Prosodic influences on phonetic realizations of four Dutch consonants (/t $\mathrm{d} \mathrm{s} z /$ ) were examined. Sentences were constructed containing these consonants in word-initial position; the factors lexical stress, phrasal accent and prosodic boundary were manipulated between sentences. Eleven Dutch speakers read these sentences aloud. The patterns found in acoustic measurements of these utterances (e.g., voice onset time (VOT), consonant duration, voicing during closure, spectral center of gravity, burst energy) indicate that the low-level phonetic implementation of all four consonants is modulated by prosodic structure. Boundary effects on domain-initial segments were observed in stressed and unstressed syllables, extending previous findings which have been on stressed syllables alone. Three aspects of the data are highlighted. First, shorter VOTs were found for $/ \mathrm{t} /$ in prosodically stronger locations (stressed, accented and domaininitial), as opposed to longer VOTs in these positions in English. This suggests that prosodically driven phonetic realization is bounded by language-specific constraints on how phonetic features are specified with phonetic content: Shortened VOT in Dutch reflects enhancement of the phonetic feature $\{-$ spread glottis\}, while lengthened VOT in English reflects enhancement of $\{+$ spread glottis $\}$. Prosodic strengthening therefore appears to operate primarily at the phonetic level, such that prosodically driven enhancement of phonological contrast is determined by phonetic implementation of these (language-specific) phonetic features. Second, an accent effect was observed in stressed and unstressed syllables, and was independent of prosodic boundary size. The domain of accentuation in Dutch is thus larger than the foot. Third, within a
\end{abstract}

\footnotetext{
${ }^{*}$ Corresponding author. Tel. +82222900740

E-mail address: tcho@ hanyang.ac.kr (T. Cho).
} 
prosodic category consisting of those utterances with a boundary tone but no pause, tokens with syntactically defined Phonological Phrase boundaries could be differentiated from the other tokens. This syntactic influence on prosodic phrasing implies the existence of an intermediate-level phrase in the prosodic hierarchy of Dutch.

(C) 2005 Elsevier Ltd. All rights reserved.

\section{Introduction}

Numerous recent studies have shown that the prosodic structure of spoken language is manifested in the speech signal by fine-grained phonetic details (e.g., for within-word level effects, see Cambier-Langeveld \& Turk, 1999; Krakow, 1999; Turk \& White, 1999; Turk \& ShattuckHufnagel, 2000; for phrase-level effects, see Jun, 1995; Fougeron \& Keating, 1997; Byrd, 2000; Byrd, Kaun, Narayanan, \& Saltzman, 2000; Cho \& Keating, 2001; Fougeron, 2001; Cho, 2002, 2005, in press; Byrd \& Saltzman, 2003; Tabain, 2003a, b; Keating, Cho, Fougeron, \& Hsu, 2003). Such evidence makes clear that the physical realizations of sounds can never be characterized adequately without the influence of prosodic structure on them being taken into account. In this study, we examine the effect of prosodic structure on the realization of four consonants (the stops $/ \mathrm{t} \mathrm{d} /$ and the fricatives $/ \mathrm{s} \mathrm{z} /$ ) in Dutch.

Most theories regarding prosodic organization (e.g., Selkirk, 1984; Beckman \& Pierrehumbert, 1986; Nespor \& Vogel, 1986) presuppose that phonological units are organized in hierarchically nested prosodic structure where lower prosodic constituents (e.g., syllables) are grouped into immediately higher levels (e.g., Prosodic Word), up to a largest prosodic constituent such as the Intonational Phrase or the Utterance (see Shattuck-Hufnagel \& Turk, 1996, for review). Such prosodic organization is often entwined with stress and accent, which are taken to be the linguistic manifestations of rhythmic structure, varying in degree of prominence across prosodic levels (e.g., Liberman \& Prince, 1977; Beckman, 1986; Hayes, 1989; de Jong, Beckman, \& Edwards, 1993; Beckman \& Edwards, 1994; see Cutler, 2001, for definitions of prosody). For example, the lexically stressed syllable is defined as the head of the Prosodic Word, and the syllable receiving phrasal accent as the head of the phrase (Beckman \& Edwards, 1994). In the present study, prosodic structure is therefore defined as reflecting not only phrasal organization (or the grouping of phonological units) but also the relative salience of phonological units as determined by lexical stress and phrasal accent.

Previous studies have examined one or more of these three factors. Thus, e.g., segments are produced with longer duration in lexically stressed syllables vs. unstressed syllables in English (e.g., Lehiste, 1970; Klatt, 1976); in (pitch-)accented syllables vs. unaccented syllables in Dutch (Cambier-Langeveld \& Turk, 1999) and English (de Jong, 1995; Cambier-Langeveld \& Turk, 1999; Cho, 2002, in press); and at a prosodic boundary or at edges of prosodic constituents vs. when embedded within a prosodic constituent (for preboundary lengthening see, e.g., Wightman, Shattuck-Hufnagel, Ostendorf, \& Price, 1992, for English; Hofhuis, Gussenhoven, \& Rietveld, 1995, for Dutch; for postboundary lengthening, see Fougeron \& Keating, 1997, for English; Cho \& Keating, 2001, for Korean; and Fougeron, 2001, for French; see also Cambier-Langeveld, 1999, 2000, for interactions between preboundary lengthening and accentual lengthening in Dutch and English). 
These studies suggest that the phonetic manifestation of prosodic structure can be understood in terms of how segments are phonetically realized in prosodically 'strong' locations such as in lexically stressed and accented syllables and at the edges of prosodic constituents. To our knowledge, however, no study to date has explored, in parallel and within a single language, the effects of these multiple prosodic factors on segmental realization in postboundary position. For example, the effects of accent and prosodic boundary on postboundary consonants were examined by Cho (2002, in press) without consideration of the lexical stress factor. All three factors were considered by Edwards, Beckman, and Fletcher (1991), but their study was limited to effects on preboundary syllables. In investigating the accent-induced lengthening effect (also known as accentual lengthening), Turk and her colleagues considered lexical stress and accent, but without considering prosodic boundaries higher than the Prosodic Word boundary (Turk \& Sawusch, 1997; Cambier-Langeveld \& Turk, 1999; Turk \& White, 1999; cf. Sluiter, 1995; de Jong \& Zawaydeh, 2002). Cambier-Langeveld's (1999, 2000) study on the interaction between preboundary lengthening and accentual lengthening in Dutch did not factor in lexical stress. Furthermore, most studies that have investigated domain-initial strengthening (i.e., spatiotemporal expansion of domain-initial segments as compared to domain-medial ones) have been limited to stressed initial consonants (Pierrehumbert \& Talkin, 1992; Fougeron \& Keating, 1997; Cho, 2002).

We therefore undertook to measure, within a single experiment, the influence of prosodic boundaries, phrasal accent and lexical stress on consonant realization in postboundary position in Dutch. We were thus able to explore not only the effects of each of these three prosodic factors, but also their potential interaction. That is, we could test whether the phonetic patterns arising apparently from one of the prosodic factors are further constrained by the other two factors.

An interaction between the effects of lexical stress and prosodic boundary on consonant production could be informative about the generality of domain-initial strengthening. As noted above, most previous studies have examined initial strengthening in stressed syllables alone. If such strengthening is restricted to stressed syllables, there should be no effect of prosodic constituent size on unstressed initial syllables. If, however, strengthening is a more general phenomenon, there should be no interaction between stress and boundary size, i.e., both stressed and unstressed syllables should show the domain-initial strengthening effect.

Interactions involving the accent factor could be informative about the domain of accentuation in Dutch. Eefting (1991) has argued that accentual lengthening in Dutch (i.e., lengthening of segments in an accented word) applies not only to the stressed syllable of the accented word, but also to unstressed syllables to the left of the stressed syllable. Although Turk and Sawusch (1997) suggested that accentual lengthening in English spreads mainly rightward from a stressed syllable to following unstressed syllables, in contrast to the Dutch case, subsequent studies (CambierLangeveld \& Turk, 1999; Turk \& White, 1999) have shown that there is small but reliable leftward spreading of accentuation in both languages. We tested the domain of accentuation in Dutch further, by examining the accentuation effect in the context of various prosodic boundaries. If accentuation does apply to the whole Prosodic Word or even beyond it, there should be no interactions between the effects of the stress and accent factors, i.e., both stressed and unstressed initial syllables should show the accentual effect. Furthermore, if the accentual effect is independent of prosodic boundary strength, there should be no three-way interaction, i.e., the 
accentuation effect should be maintained regardless of stress and of the size of the prosodic boundary.

Our primary goal was hence to develop a clearer understanding of the prosody-phonetics interface. How is the phonetic realization of Dutch consonants conditioned by the three different types of prosodic factors in Dutch utterances? How does the phonetic pattern that arises from one factor differ from those that arise from the other two? From the perspective of the listener rather than the speaker, we also sought to establish how high-level prosodic structure is signaled by systematicities that may be found in the phonetic details associated with consonant production.

We also tested the language-specificity of the prosody-phonetics interface. Specifically, we compared how voiceless stops are acoustically realized in prosodically strong locations in Dutch with their realization in English. Voiceless stops in English are generally produced with longer voice onset times (VOTs) in prosodically stronger locations (i.e., in lexically stressed, phraseaccented and domain-initial syllables; see, e.g., Lisker \& Abramson, 1967; Pierrehumbert \& Talkin, 1992; Cooper, 1991; Choi, 2003; Cole, Choi, Kim, \& Hasegawa-Johnson, 2003). Such an increase in VOT has been interpreted as one of the most robust consonantal phonetic cues to prosodic structure. Studies on other languages have shown similar prosodic influences on VOT. Although all such studies have shown some increase in VOT in prosodically stronger locations, clearer VOT patterns have been found in Korean (Cho \& Keating, 2001) and Taiwanese (Hayashi, Hsu, \& Keating, 1999) than in French (Fougeron, 1999, 2001) and Japanese (Onaka, Palethorpe, Watson, \& Harrington, 2002). (See Hacopian, 2003, for prosodic influences on the three-way stop voicing contrast in final position in Armenian.)

Of particular interest is variation in VOT in Korean, which has a three-way contrast among fortis, lenis and aspirated versions of voiceless stops (e.g., Cho, Jun, \& Ladefoged, 2002). VOT is one of the most robust phonetic cues for this three-way contrast, with the shortest VOT for the fortis stop and the longest for the aspirated stop (e.g., Cho et al., 2002). Cho and Jun (2000) showed that while lenis and aspirated stops are produced systematically with a progressively longer VOT after a higher prosodic boundary, there is no such prosodic influence on VOT for fortis stops. They interpreted the lack of VOT effect for fortis stops as coming from the phonological system - an increase in VOT for the fortis stop would reduce its phonetic contrast with the other stops.

This interpretation is consistent with findings in English that segments are strongly articulated or 'hyperarticulated' in prosodically stronger locations in a way that may maximize phonological contrast (de Jong, 1995; Cho, 2002, 2005). De Jong (1995) showed that tongue position for the English vowel $/ \mathrm{U} /$ is more posterior in accented syllables than in nonaccented syllables. Similarly, lip opening for vowels /a, i/ in English is larger at the edges of higher prosodic boundaries than at the edges of lower ones (Cho, 2005). It has also been shown that vowels are coarticulated less with neighboring segments in prosodically stronger locations (Cho, 2004). This suggests that phonological contrast can be enhanced through coarticulatory resistance at stronger prosodic locations. Note, however, that the effect of prosodic strengthening on phonological contrast may also vary depending on its source. Cho (2005) reported in a production study of vowel articulation that the tongue is more fronted for $/ \mathrm{i} /$ when the source of strengthening is accentuation (i.e., in accented syllables vs. nonaccented syllables), whereas the tongue is more raised (but not fronted) when prosodic strengthening comes from the boundary (i.e., before a higher prosodic boundary vs. before a lower prosodic boundary). These findings 
suggest that the effects of accent and boundary on the enhancement of phonological contrast can be different.

Seen in the light of these effects on phonological contrast, the results of Cho and Jun (2000) thus imply that VOT may not be uniformly subject to an increase in prosodically strong locations, but rather that it can be further modulated by the language-specific contrasts in the phonological system. The strong articulation associated with stressed and accented syllables can result in an enhancement of paradigmatic contrast, i.e., an enhancement of distinctive features in ways that maximize lexical contrast, as proposed by de Jong (1995). The longer VOT associated with English voiceless stops in prosodically stronger locations can thus be interpreted as giving rise to an enhancement of paradigmatic contrast between 'voiceless' and 'voiced' stops (/t/ vs. /d/).

The present study therefore tested whether Dutch voiceless stops are produced in much the same way as in other languages (i.e., with longer VOTs in prosodically stronger locations). Given that Dutch is similar to English in many aspects of prosody (i.e., they are both stress-accent languages; Cambier-Langeveld, 2000), one might predict that prosodic modulation of VOT in Dutch voiceless stops would pattern in the same way as that in English voiceless stops, such that the lengthened VOT may enhance phonological contrast between 'voiceless' and 'voiced' stops just like in English.

Note, however, that while /d/ and / $\mathrm{t} /$ in English, especially in initial position, are phonetically realized as voiceless unaspirated vs. aspirated, with the voicing contrast being mediated by the amount of aspiration, the voicing contrast in Dutch depends primarily on the presence vs. the absence of prevoicing, with $/ \mathrm{d} /$ and $/ \mathrm{t} /$ being realized as voiced vs. voiceless unaspirated (van Alphen \& Smits, 2004). This cross-linguistic difference leads to the prediction that there will be different prosodic modulations of VOT in Dutch and English. Following Keating (1984a, 1990), while the 'phonological' feature $[ \pm$ voice] is required to explain the phonological contrast between voiced and voiceless stops within each language (see also Kingston \& Diehl, 1994), the 'phonetic' feature $\{ \pm$ spread glottis $\}$ is required to explain the difference in implementation in voiceless stops between languages. (Note that, following Keating, 1984a, curly brackets ' \{\} ' are used here to refer to phonetic features.) On the one hand, English voiceless stops may be specified as $\{+$ spread glottis\}, which could be phonetically implemented so as to result in relatively long VOTs (aspiration). On the other hand, Dutch voiceless stops may be specified as $\{-$ spread glottis\}, resulting in relatively short VOTs (less aspiration). If prosodic modulation of VOT reflects the enhancement of these language-specific phonetic features (i.e., $\{+$ spread glottis $\}$ vs. $\{-$ spread glottis\}), a cross-linguistic difference in the VOT pattern could therefore arise. The increased VOT for $/ \mathrm{t} /$ at prosodically stronger locations in English could reflect enhancement of $\{+$ spread glottis\}. If prosodic strengthening of voiceless stops in Dutch reflects the enhancement of $\{$-spread glottis $\}$, shorter VOTs at stronger positions should be found, even if shortened VOTs would work against the phonological contrast, if one adopted the view that the phonological voicing contrast is maximized by the principle of polarization along the VOT continuum.

Alternatively, however, because voiced stops (e.g., /d/) in Dutch are phonetically implemented typically via vocal fold vibrations during the closure, and because enhancement of the phonetic feature $\{-$ spread glottis $\}$ for voiceless stops (e.g., /t/) likely counters the phonological contrast, one might predict that the phonological contrast between voiced and voiceless stops in Dutch may be enhanced primarily by an increase in the amount of prevoicing in the voiced stops. Voicing is 
facilitated by slack vocal folds (cf. Halle \& Stevens, 1971). As a reviewer pointed out, therefore, the phonetic feature $\{+$ slack vocal folds $\}$ could be enhanced for voiced stops, rather than the feature $\{-$ spread glottis $\}$ for voiceless stops. The prediction would then be that there would be no prosodic effect on VOT which was directly related to the implementation of $\{ \pm$ spread glottis\}, but that the amount of prevoicing would be prosodically modulated in a way that would enhance the voicing contrast in a prosodically strong position.

In summary, the present study explored how the Dutch stops $/ \mathrm{t} d /$ and the fricatives $/ \mathrm{s} \mathrm{z} /$ are acoustically realized in prosodically stronger vs. weaker locations. Three different prosodic factors were manipulated: We compared realizations of the consonants in stressed vs. unstressed syllables, in accented vs. unaccented position, and in domain-initial position in prosodic constituents of five different types (see below). We tested whether, as in other languages, the realization of postboundary Dutch consonants is modulated by these three factors. Critically, however, we were also able to test for possible interactions in the effects of these factors. In the specific case of $/ \mathrm{t} /$, we examined whether prosodic strengthening is language specific and, in so doing, we tested accounts of prosodic strengthening based on enhancement of phonological contrast vs. language-specific phonetic content (associated with phonetic features).

In addition, we tried to establish how many different levels of prosodic constituents can be phonetically differentiated in Dutch. Although there has been some disagreement with respect to whether the intonational description of Dutch should be based on distinctive pitch movements (e.g., Collier \& 't Hart, 1981; 't Hart, Collier, \& Cohen, 1990) or pitch targets and tonal inventories (e.g., Gussenhoven, 1988; Gussenhoven, Rietveld, \& Terken, 1999), what has been agreed on is that Intonational Phrase boundaries can be differentiated from Prosodic Word boundaries via intonational and durational characteristics, especially toward the end of constituents. Unlike English, however, in which relatively clear criteria have been set up to define the Intermediate Phrase (Beckman \& Pierrehumbert, 1986; see Beckman \& Elam, 1997; Silverman et al., 1992, for a prosodic transcription system in American English, tone and break index $[\mathrm{ToBI}])$, there have been no widely accepted transcriptional criteria which may differentiate between the Intonational Phrase and a potential intermediate-level phrase in Dutch.

The Phonological Phrase ( $\mathrm{PhP})$ has been proposed as an intermediate-level phrase by some researchers (e.g., Selkirk, 1986; Nespor \& Vogel, 1986; Cambier-Langeveld, Nespor, \& van Heuven, 1997; Cambier-Langeveld, 2000), but it is defined in syntactic terms. Although prosodic structure is constrained by syntax, there are many other factors such as length (the number of words or syllables in a constituent) and speech rate that can override syntactic constraints, resulting in restructuring of the syntactically based default prosody (e.g., Nespor \& Vogel, 1986; Jun, 1993; Keating \& Shattuck-Hufnagel, 2003). In addition, the default prosody can further be revised according to other communicative demands such as speakers' 'communicative and expressive intent' (cf. Keating \& Shattuck-Hufnagel, 2003). The syntactically defined string of segments in a given utterance therefore does not completely determine its surface prosodic pattern. Nevertheless, even though there are no established phonetic criteria for intermediate-level phrases like the PhP or the Intermediate Phrase in Dutch, one can still examine whether certain syntactically defined phrases such as PhPs tend to induce consistent phonetic patterns that would allow such phrases to be distinguished from Intonational Phrases and/or Prosodic Words. The present speech materials included a syntactically defined $\mathrm{PhP}$ to test this possibility. 


\section{Methods}

\subsection{Participants}

Eleven native speakers of Dutch (six females and five males) were paid for their participation. They were all undergraduate students at the University of Nijmegen. We ensured that none of them spoke Limburg dialects, because these are known to have different prosodic systems from other varieties of Dutch (cf. Gussenhoven, 2004; Gussenhoven \& Driessen, 2004). Our analyses and claims are based on the performance of the group of speakers as a whole; any remaining dialect differences among speakers that may exist were not examined.

\subsection{Test sentences and procedure}

The test consonants were two anterior coronal stops (/t d/) and two sibilant fricatives $(/ \mathrm{s} \mathrm{z} /)$ in word onset position. These consonants appeared in both stressed and unstressed syllables in a

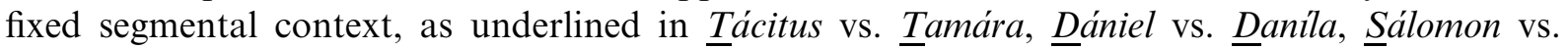
$\underline{S}$ alóma and Źára vs. Zadók. For accent placements, two different versions of each sentence were produced: one with accent falling on the target word (e.g., Tacitus, the first name of an individual) and one with accent on the next word (e.g., de Vries, the last name, as in Tacitus de Vries). In order to induce the desired variety of accent-placement patterns, words to be accented were written in bold uppercase in the script, and speakers were introduced to discourse situations in which the target sentences could occur. Note that when initial test consonants occurred in unstressed syllables of accented words (as in Tamára, Danila, Salóma, Zadók), the accent fell in theory on the second (stressed) syllables in the words. Therefore, when it is said in the present study that test consonants in unstressed syllables are accented, it means that the whole targetbearing words are accented with the test consonants being in pre-accented syllables. Nevertheless, as discussed in Section 1, the present study explores the extent to which accentuation influences the articulation of the unstressed initial consonant, by examining interactions between the accent and stress factors.

An example set of sentences for $/ t /$ is shown in Table 1 . The full set of test sentences is given in Appendix A. The same sentence frames as in Table 1 were used for other consonants. The only

Table 1

An example set of sentences containing / $t /$
(a) Utterance
Roel ging naar mijn opa. Tacitus de Vries was gisteren jarig.
(b) Vocative
Roel went to my grandpa. It was Tacitus de Vries' birthday yesterday.
(c) List
Zeg eens opa, Tacitus de Vries is net aangekomen.
Say, grandpa, Tacitus de Vries has just arrived.
Vandaag gingen mijn opa, Tacitus de Vries en Zara de trap af.
(d) Phonological Phrase
Today, my grandpa, Tacitus de Vries and Zara went down the stairs.
Dan gaat mijn opa Tacitus de Vries helpen inpakken.
(e) Prosodic Word
Then my grandpa is going to help Tacitus de Vries to pack.
Vanmorgen ging opa Tacitus de Vries de trap af.
This morning, grandpa Tacitus de Vries went down the stairs 
difference was that for female names (e.g., Tamara, Danila, Saloma, Zara), oma ('grandmother') was used instead of opa ('grandfather').

Five different sentence types were used so that the target consonants occurred at beginnings of prosodic constituents of potentially different size. The first sentence type had an utterance boundary which was punctuated by a period. The second type had a vocative boundary. The third had the target consonant in a list with a boundary between enumerated items. The fourth contained a boundary between an NP and a VP in which the V and NP were inverted (due to the adverb dan 'then' starting the sentence). This resulted in an NP (subject)-NP (object) sequence (mijn opa-Tacitus de Vries). Such inversion induces a PhP boundary between the two NPs. Crucially the head noun opa in the subject NP (mijn opa 'my grandfather') forms the end of its maximal projection (NP), constituting a syntactically defined PhP (e.g., Selkirk, 1986; Nespor \& Vogel, 1986; see Marsi, 2001, for further discussion on the domain of the PhP in Dutch). The fifth sentence type had only a Prosodic Word boundary before the critical consonant.

Before data collection, speakers practiced saying the speech materials for $20-30 \mathrm{~min}$. This was done so that the speakers could become familiar with the materials, and thus be able to produce the intended renditions of the sentences fluently. In particular, speakers required practice in placing accents in the positions we intended. Speakers rehearsed all sentence types equally. A reviewer noted that practicing speech materials in advance might have induced 'hyperarticulation' of the syntactic distinctions manipulated in the experiment. We agree that speech data acquired in a laboratory setting with prior practice may represent one extreme of a continuum of acoustic effects conditioned by prosody. It remains to be determined whether the same patterns will be found in spontaneous speech. After familiarization, the speakers repeated each sentence three times in a pseudo-randomized order. In total, 2640 sentence tokens were collected (4 consonants $\times 2$ stress levels $\times 2$ accent levels $\times 5$ sentence types $\times 11$ speakers $\times 3$ repetitions).

As mentioned in Section 1, there is no agreed-upon prosodic transcription system in Dutch, especially with respect to defining an intermediate-level phrase. An independent and less controversial scale was therefore used to group the obtained data into possible prosodic constituents of different size. De Pijper and Sanderman (1994) showed that Dutch listeners' judgments of boundary strength could be grouped according to three acoustic-phonetic cues: "melodic discontinuity", "pause" and "baseline reset" of pitch. In brief, perceived boundary strength was in general stronger when there was a pause than when there was not, and it was weakest when there is no pause and no melodic discontinuity. Perceived boundary strength was also strongly correlated with preboundary lengthening, which is known to be one of the most robust prosodic features that is correlated with level of prosodic boundary (Wightman et al., 1992; Cambier-Langeveld, 2000). Furthermore, Gussenhoven et al. (1999) developed a transcription system of Intonation in Dutch (called ToDI) in which the Intonational Phrase boundary can be tonally differentiated from the Prosodic Word boundary. Thus, in the present study, following both de Pijper and Sanderman and Gussenhoven et al., the sentences were divided into three prosodic groups according to their prosodic boundary strengths, as determined by the presence or absence of a pause and a boundary tone:

(1) Big Phrase (BG): boundary tone and pause (strongest).

(2) Small Phrase (SM): boundary tone and no pause (intermediate).

(3) Prosodic Word (WD): no boundary tone and no pause (weakest). 
It is important to emphasize, however, that we do not want to claim that the prosodic structure of Dutch should be categorized in any formal way into these three groups. Instead, this categorization was required for the present analysis: It allowed us to examine consonantal realizations as a function of prosodic strength without needing to make strong assumptions about the theoretical status of intermediate-level phrases in Dutch. By assuming three levels of prosodic boundary, we could test whether the presence or absence of pauses and boundary tones give rise to different acoustic effects on the realization of the postboundary consonants.

The tonal transcriptions were made by three trained transcribers (two native speakers of Dutch and the first author), with the aid of a pitch track display. This was to establish whether sentences with no pause had a boundary tone or not, since this was an important criterion to group sentence tokens into the SM vs. Prosodic Word categories. Out of 1464 sentence tokens that did not contain a pause, the transcribers reached agreement on transcriptions of 1389 tokens $(94.9 \%)$. For the remaining 75 tokens, tonal transcriptions agreed by two transcribers were chosen.

Distributions of test sentences per boundary type and per sentence type are summarized in Appendix B. As shown in Appendix B.A, the BG category was composed mainly of three sentence types: the Utterance, the Vocative, and the List sentences $(44.3 \%, 38.4 \%$ and $13.9 \%$, respectively), while the PhP sentences added 3\%. The SM category was also composed mainly of three sentence types: the List, the PhP, and the Vocative sentences $(39.6 \%, 51.3 \%$ and $8.3 \%$, respectively). Finally, $96.7 \%$ of the WD category were Phonological Word sentences, and the rest were $\mathrm{PhP}$ sentences. The distributions of boundary types were also considered per sentence type (see Appendix B.B). Nearly $99 \%$ of the Utterance sentences fell in the BG category, and $99 \%$ of the Prosodic Word sentences fell in the WD category. The other sentence types were distributed over more than one category. Of particular interest is the distribution of $\mathrm{PhP}$ sentences: Although they were distributed over all three categories, the majority of them (89.2\%) fell on SM, showing a tendency toward a syntactically biased intermediate prosodic grouping.

Defining the BG category in terms of the presence of pauses is problematic with sentences with stops, because a pause is not differentiated from a stop closure in the acoustic signal. In this study, the pause before stops was defined, separately for each speaker, as any period of silence exceeding double the mean closure duration of that stop when produced by that speaker in the WD sentences (see Table 1e). Although data with respect to the pause element with stop consonants in BG must therefore be interpreted with caution, defining the pause this way is more consistent and less controversial than applying a fixed threshold (e.g., $100 \mathrm{~ms}$ ) to every speaker's data (as in, e.g., de Pijper \& Sanderman, 1994). Furthermore, as shown in Appendix B.A, the distribution of sentence types with stops within the BG category is remarkably similar to those with fricatives. For fricatives, of course, pauses were detectable in the acoustic signal. The consistency of the pattern across the stop and fricative materials suggests that the definition used to define pauses in the stop stimuli was a valid one (and for further validation, see Section 3.1).

Fig. 1 gives partial prosodic transcriptions of an example set of sentences for stressed $/ d /$ as produced in an unaccented word Dániel by speaker MN. The tonal transcriptions are based on ToDI (Gussenhoven et al., 1999). In this particular example set, the Utterance and Vocative sentences both have a pause and a boundary tone (Figs. 1a and b); they were thus grouped together in the BG category. Both the List and $\mathrm{PhP}$ sentences have a boundary tone with no pause; they were grouped together in the SM category (Figs. 1c and d). The last sentence (Fig. 1e) has no pause and no boundary tone, so was placed in the Prosodic Word category. It is important 

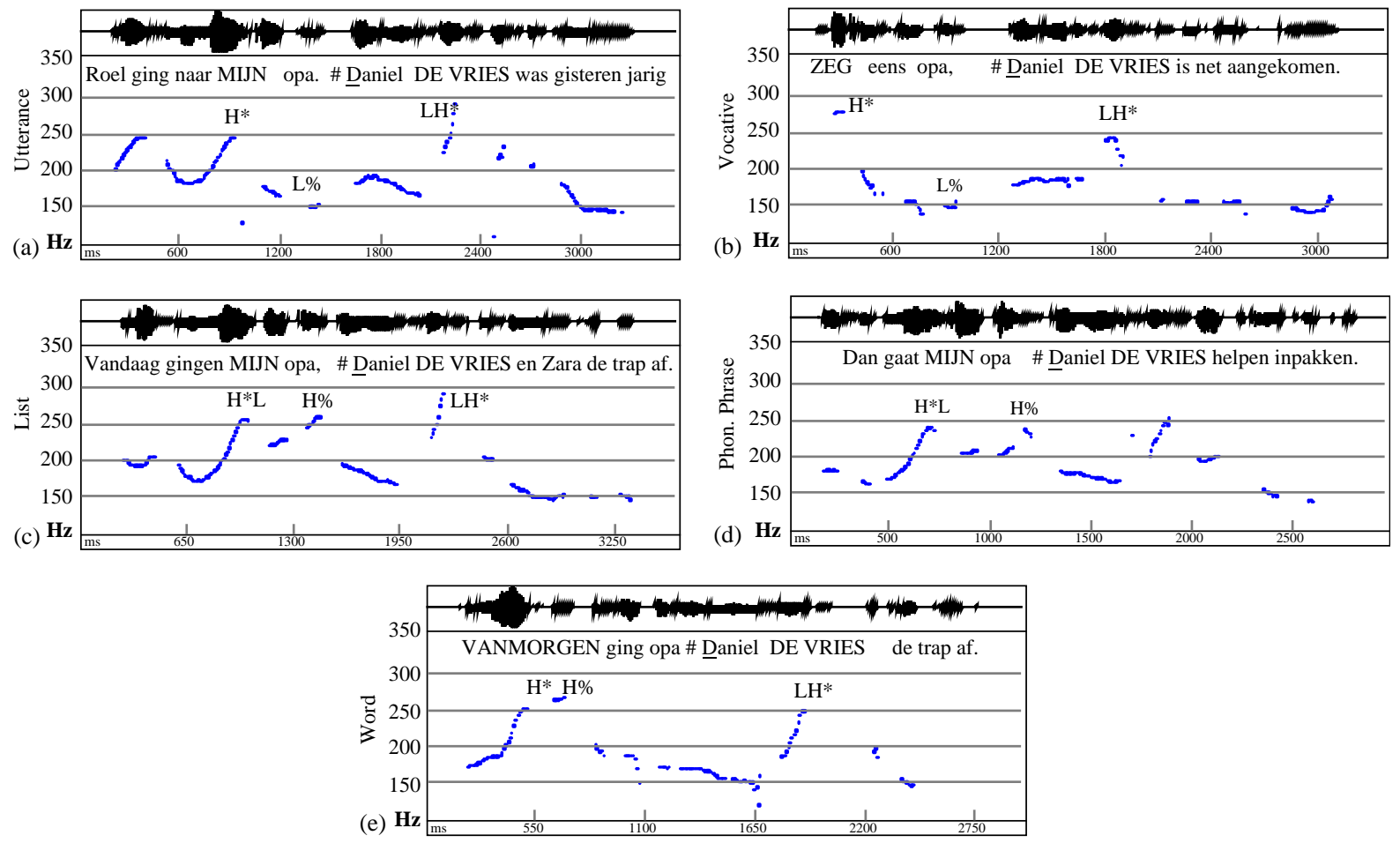

Fig. 1. An example set of the five sentence types used in the experiment. The intonational transcription was made based on ToDI (Gussenhoven et al., 1999).

to note, however, that although in this specific example, Vocative happens to be aligned with BG, and List and PhPs with SM, this was not always the case, as just discussed (see Appendix B).

\subsection{Acoustic measurements}

\subsubsection{All consonants}

- Duration of preboundary (final) syllable: Duration of the preboundary CV syllable (e.g., /pa\#/ in opa\#Daniel) was measured to examine preboundary lengthening phenomena. This measure was taken from the offset of the second formant $(F 2)$ in the preceding vowel (e.g., /o/ in opa) to the offset of $F 2$ in the preboundary vowel /a/.

- Duration of postboundary vowel in \#CV: Duration of the vowel in the postboundary syllable (e.g., /a/ in \#Daniel) was measured (from the onset to the offset of its F2) to test the extent to which the duration of the vowel after the test consonant is influenced by prosodic structure.

\subsubsection{Stops}

- Closure duration of $/ \mathrm{t} \mathrm{d} /$ : Acoustic closure duration for the stop consonants $/ \mathrm{t} \mathrm{d} /$ was taken from the spectrograms and the waveforms combined, for tokens that belonged to the SM and 
the Word conditions (BG tokens were excluded because they contained a pause). This measure was taken from the onset of F2 in the preceding vowel to the beginning of the stop burst.

- VOT of / $\mathrm{t} /$ : VOTs for $/ \mathrm{t} /$ were measured from the point of the stop release to the voice onset of $\mathrm{F} 2$ in the following vowel, as shown in spectrograms.

- Voicing during stop closure of /d/: The amount of voicing for /d/ was measured by taking the voiced interval during stop closure of $/ \mathrm{d} /$ between the onset of the voicing and the point of the release just before the following vowel. When there was no clear release, the onset of F2 in the vowel was taken as the offset of the stop voicing. (Note that after $/ \mathrm{d} /, \mathrm{F} 1$ and F2 of the following vowel were almost always in synchrony.) The presence of voicing during the closure was checked by inspecting both the voicing bar (glottal pulsing) at the bottom of the spectrogram and the periodicity in the waveform. In cases of doubt (i.e., where the glottal pulsing was detectable only marginally in one display, but not in the other display), the portion was not included.

- RMS burst energy: The acoustic energy at the burst was measured from an FFT spectrum giving the RMS value over a frequency range from 1000 to $10,000 \mathrm{~Hz}$. (The frequency range below $1000 \mathrm{~Hz}$ was excluded in order to avoid the influence of potential voicing around the release, especially for $/ \mathrm{d} /$.) A 256-point $(12.8 \mathrm{~ms})$ hamming window was centered over the release of the stops $/ \mathrm{t} \mathrm{d} /$, covering the first $6.4 \mathrm{~ms}$ of the burst and thus preventing the window from including any following vocalic energy.

- Spectral center of gravity (COG) of stop burst: The spectral COG, also known as the first spectral moment, is the centroid frequency of a defined part of the spectrum, each frequency being weighted according to its amplitude. COG was taken from the same FFT spectra as was used for RMS burst energy measurement. Frequencies (over all samples between 1000 and $10,000 \mathrm{~Hz}$ ) were multiplied by the corresponding spectral energies. The sum of these products over the entire frequency range was then divided by the sum of the spectral energies, yielding the centroid frequency.

\subsubsection{Fricatives}

- Frication duration of /s z/: Acoustic frication duration for the fricatives /s z/ was taken from the onset of aperiodic acoustic noises to the onset of $F 2$ in the following vowel. The fricative noises were indicated by high frequency noises displayed in the spectrogram, which were cross-checked by the presence of aperiodic noises in the waveform.

- Voicing during /z/: The amount of voicing for /z/ was measured by taking the voiced interval during frication for $/ z /$, as indicated by both the voicing bar in the spectrogram and the waveform. The fricative voicing in the waveform was typically characterized by the baseline oscillation pattern reflecting vocal fold vibrations, upon which complex higher frequency noise components were superimposed. Thus, when there was doubt about the presence or the beginning and end of the voicing bar in the spectrogram, the presence of the baseline oscillation pattern with complex noise components was used as the more decisive measurement criterion. Finally, when the voiced frication continued into the following vowel as often seen on the spectrogram, the onset of $F 2$ was taken as the offset of voicing associated with the fricative. 
- RMS frication energy: The acoustic energy was measured from an FFT spectrum giving the RMS value over a frequency range of $1000-10,000 \mathrm{~Hz}$. A 1024-point $(51.2 \mathrm{~ms})$ hamming window was centered over at the midpoint of the frication.

- Spectral COG for /s z/: COG for /s z/ was obtained in the same way as for the stop burst, except that a larger window was used (that used in the computation of RMS frication energy).

The durational measurements were obtained using Praat, while all the spectral analyses were done with Kay Elemetrics's Multispeech.

\subsubsection{Relationship to articulation}

There are several points to note about the relationship between these acoustic measures and the strength and nature of articulation. First, consonant duration measures are generally correlated with degree of consonantal strength as a function of prosodic structure - the longer the consonant duration, the stronger the articulation (e.g., Fougeron \& Keating, 1997; Cho \& Keating, 2001). Second, measures such as VOT for $/ \mathrm{t} /$ and voicing duration for $/ \mathrm{d}$, $\mathrm{z} /$, being related to laryngeal articulation, reflect degree of voicing - the longer the VOT, the larger the glottis opening; the more the voicing during the consonant, the more active the articulatory gesture is (e.g., there may be more active expansion of the vocal tract for aerodynamic reasons; Westbury, 1983; Keating, 1984b). Third, RMS burst energy for /t d/ may reflect articulatory/aerodynamic properties associated with the stop release gesture. It may indicate degree of oral pressure behind the oral constriction. All else being equal, higher oral pressure buildup during the stop closure may result in higher RMS burst energy. It may also indicate degree of linguopalatal contact for lingual consonants - greater contact would give a longer release duration, and thus less peak burst energy (Stevens, Keyser, \& Kawasaki, 1986). Furthermore, it may at least in part be correlated with the speed of the release - the faster the release tongue movement, the higher the RMS burst energy (see Cho \& Keating, 2001, for some discussion). Fourth, one of the possible inferences that can be made from the spectral COG at the stop release and during the fricative is about a potential shift of place of articulation. For example, for the alveolar fricatives /s z/, a high centroid is expected as the source is filtered by the front cavity resonance, resulting in a spectrum peak in the vicinity of F4 or F5 (Stevens, 1999). We were particularly interested in determining whether there was systematic variation in COG as a function of prosodic structure. This could indicate a difference in the size of the front cavity - the higher the frequency, the smaller the front cavity (Forrest, Weismer, Milenkovic, \& Dougall, 1988; Zsiga, 1993; Harrington \& Cassidy, 1999).

\subsection{Data analysis}

The data were averaged over repetitions so that each subject contributed only one experimental score per condition. This reduction in data guaranteed that the error effects in the analyses of variance (ANOVAs) were independent (Kirk, 1995; Max \& Onghena, 1999). Failure to make this kind of data reduction can artificially inflate error terms and degrees of freedom, and thus can increase the likelihood of making a Type I or $\alpha$ error (i.e., of drawing the incorrect conclusion that a nonexistent effect is real). Evaluation of the systematic influence of various prosodic factors was made based on repeated measures General Linear Model ANOVAs. The within-subject factors considered were Stress (stressed vs. unstressed), Accent (accented vs. unaccented) and Prosodic 
Boundary (BG, SM and WD). In order to avoid violating the sphericity assumption (i.e., the assumption that the variance of the difference scores for all pairs of treatment levels are homogeneous; Huynh \& Feldt, 1970; Max \& Onghena, 1999), Huynh-Feldt corrected degrees of freedom were used in generating $F$ ratio and $p$-values. As a result, degrees of freedom are often reduced to fractional values, as reported in the present study (e.g., $F[2,10] \rightarrow F[1.6,9.6])$. In order to further analyze within-factor effects, pairwise ANOVAs were also performed. In these analyses, the Bonferroni/Dunn correction was applied (this corrects for potential heterogeneous variances and correlations between repeated observations when there were more than two levels to be compared within a factor; Hays, 1994). Finally, when necessary, effect size was estimated by conducting $\eta^{2}\left(\mathrm{eta}^{2}\right)$ analyses. $\eta^{2}$-values provide a measure of how much the observed variability can be ascribed to a given factor and, therefore, how large the observed effect might be (Sheskin, 2000, pp. 553-556). In all ANOVAs, $p$-values less than 0.05 were considered significant.

\section{Results}

\subsection{Preboundary lengthening}

As preboundary lengthening has widely been considered as one of the primary phonetic correlates of prosodic structure (e.g., Wightman et al., 1992), we first examined whether our threeway prosodic grouping (based on pause and boundary tones; see Section 2.2) could be corroborated by differences among the three prosodic groups (BG, SM and WD) in the duration of the preboundary syllables. There was a significant Boundary effect on preboundary syllable $(\mathrm{CV} \#)$ duration $(F[1.4,14.5]=90.42, p<0.0001)$. Pairwise comparisons revealed that there was a three-way distinction with the pattern $\mathrm{BG}>\mathrm{SM}>\mathrm{WD}$, as shown in Fig. 2a. There was no Consonant $\times$ Boundary interaction $(F[2.8,28.9]=2.01, p=0.136)$, suggesting that the preboundary lengthening effect was consistent across consonants. Fig. $2 \mathrm{~b}$ illustrates that the effect was indeed similar across consonants. These results validate the categorization of the data into

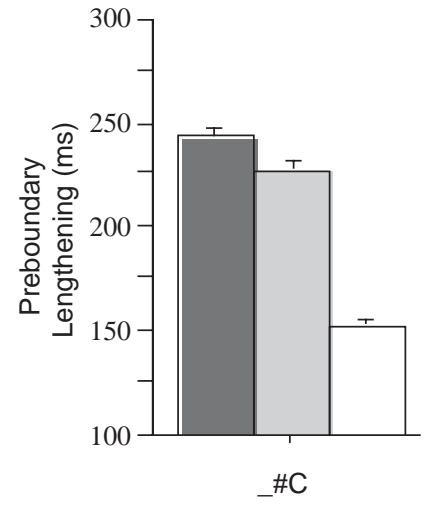

(a)

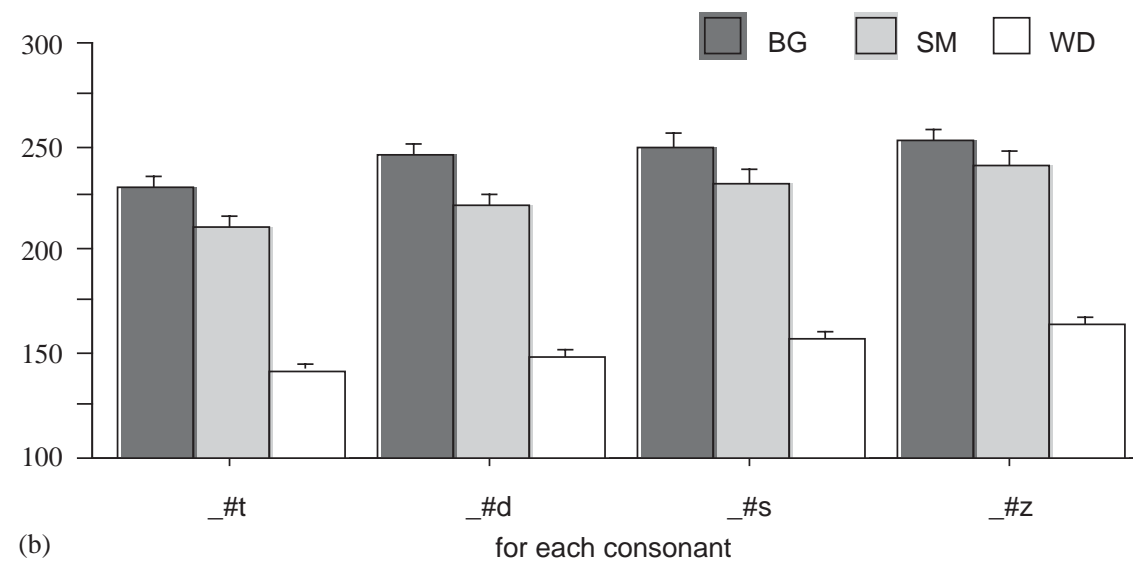

Fig. 2. Preboundary lengthening as reflected in CV\# duration. 'BG' = Big Phrase; 'SM' $=$ Small Phrase; WD = Word. Error bars refer to standard errors. 
three prosodic groups, and further diminish concerns about defining pauses before stops, as both stops and fricatives showed a consistent preboundary lengthening effect.

\section{2. $/ t /$}

\subsubsection{Closure duration of $/ t /$}

There were main effects of all three factors (Stress, Accent and Boundary) on / $t /$ closure duration, as shown in the left side of each panel in Fig. 3. Closures were significantly longer in prosodically stronger positions, i.e., longer in stressed and accented syllables than in unstressed and unaccented syllables, and longer at a stronger boundary (SM) than at a weaker boundary (WD). (Recall that for the Boundary factor, only the two levels SM and WD were analyzed because the pause and the stop closure could not be differentiated for BG.) There were no between-factor interactions.

\subsubsection{Voice onset time for $/ t /$}

There were again main effects of all three prosodic factors. VOTs were shorter for $/ \mathrm{t} / \mathrm{s}$ in stressed and accented syllables and at stronger boundaries than for $/ \mathrm{t} / \mathrm{s}$ in unstressed and unaccented syllables and at weaker boundaries, as shown in the middle of each panel in Fig. 3. Furthermore, as shown in the Stress $\times$ Accent interaction in Fig. 4a, VOT was shortest when the syllable was both accented and stressed and it was longest when the syllable was both unaccented and unstressed. That is, there was a cumulative effect of Stress and Accent on VOT. There was also a significant Stress $\times$ Boundary interaction (Fig. 4b). The effect of Boundary on VOT was

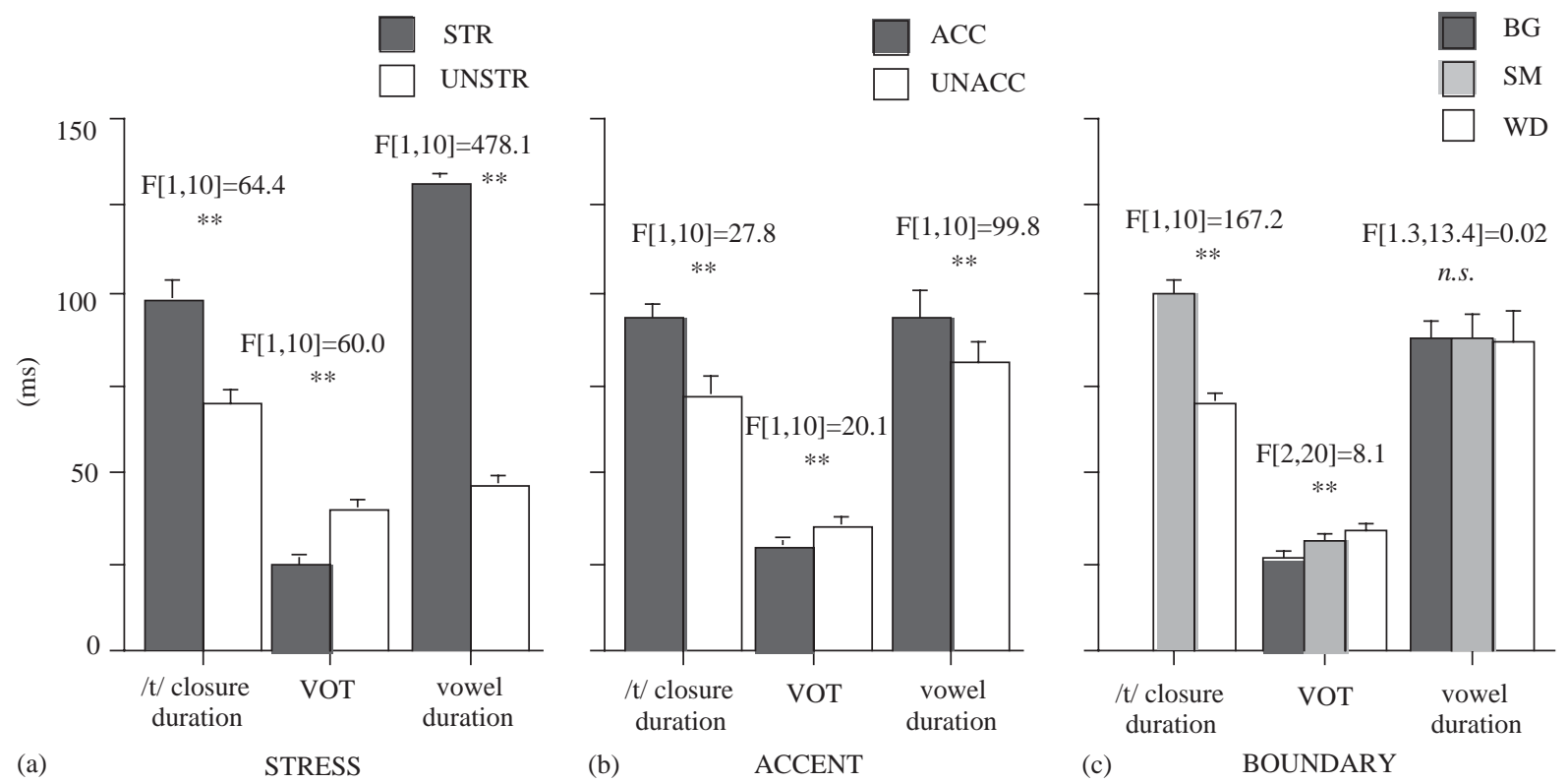

Fig. 3. $/ \mathrm{t} /$ closure duration, VOT and /a/ duration in /\#ta/. Error bars refer to standard errors. $* * p<0.001$. Note that / $\mathrm{t} /$ closure duration for BG was not included in ANOVAs due to the impossibility of separating the pause from the stop closure duration. 

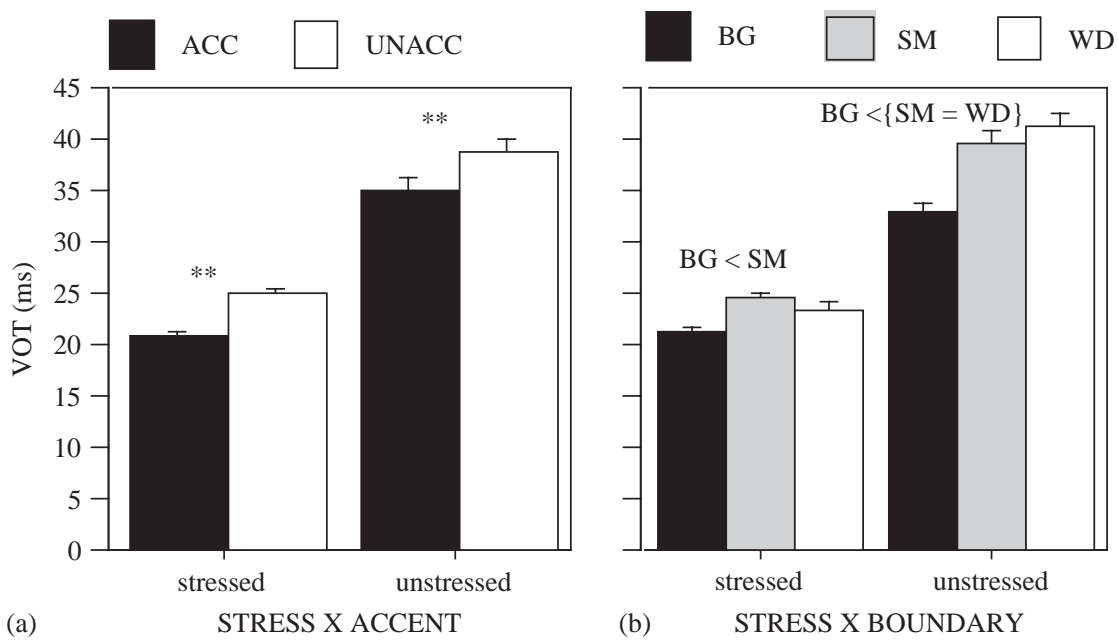

Fig. 4. Interactions in VOT. $* * p<0.001 ;<p<0.05$.

more robust when $/ \mathrm{t} /$ was unstressed $\left(\eta^{2}=0.124\right)$ than stressed $\left(\eta^{2}=0.026\right)$. Post hoc tests showed that when $/ \mathrm{t} /$ was unstressed, VOT was significantly shorter at BG boundaries than at both SM and WD boundaries, but when / $\mathrm{t}$ / was stressed, VOT at BG boundaries was significantly shorter only than that at SM boundaries. These results suggest that prosodic modulation of VOT in Dutch is different from that in English: Dutch speakers tend to produce shorter VOTs in prosodically stronger positions, while English speakers tend to produce longer VOTs in stronger positions. We will return to this issue in the Discussion.

\subsubsection{Vowel duration in /ta/}

There were effects of Stress and Accent on vowel duration: /a/ in / ta/ was longer when it was either stressed or accented, as shown in the rightmost columns in Figs. 3a and b. There was also a Stress $\times$ Accent interaction $(F[1,10]=6.75, p<0.05)$ which can be attributable to a more robust Accent effect when the syllable was stressed $\left(p<0.001, \eta^{2}=0.295\right)$ than when it was unstressed $\left(p<0.01, \eta^{2}=0.103\right)$. Although there was no effect of Boundary size on vowel duration (Fig. 3c, rightmost columns), there was a Stress $\times$ Boundary interaction $(F[1.8,17.7]=7.67, p<0.005)$. This interaction was due to the fact that there was a significant boundary effect on vowel duration (BG $>$ WD; $p<0.01)$ only when the syllable was unstressed. Thus, although the effects of boundary size were weaker than those for this factor on closure and VOT duration, boundary size does appear to influence vowel duration.

\subsubsection{RMS burst energy for / $t /$}

There was neither a main effect of any of the three prosodic factors nor a significant interaction among them on RMS burst energy (see Table 2).

\subsubsection{Spectral center of gravity for $/ t /$}

As also shown in Table 2, no significant effects of Stress and Accent were observed, but there was a significant Boundary effect. COG was significantly lower at BG boundaries than at WD 
Table 2

RMS burst energy and spectral center of gravity for $/ \mathrm{t} /$ and $/ \mathrm{d} /$

\begin{tabular}{|c|c|c|c|}
\hline & Stress & Accent & Boundary \\
\hline \multicolumn{4}{|l|}{$\mid \mathrm{t} /$} \\
\hline RMS burst energy (dB) & $\begin{array}{l}14.51 \text { vs. } 13.44 \\
\text { STR }=\text { UNSTR } \\
F[1,10]=2.97^{\text {n.s. }} \\
\text { No interactions }\end{array}$ & $\begin{array}{l}13.82 \text { vs. } 14.12 \\
\mathrm{ACC}=\mathrm{UNACC} \\
F[1,10]=0.285^{\text {n.s. }}\end{array}$ & $\begin{array}{l}14.01 \text { vs. } 14.08 \text { vs. } 13.83 \\
\mathrm{BG}=\mathrm{SM}=\mathrm{WD} \\
F[1.7,17.0]=0.339^{\text {n.s. }}\end{array}$ \\
\hline $\mathrm{COG}(\mathrm{Hz})$ & $\begin{array}{l}5038 \text { vs. } 5107 \\
\mathrm{STR}=\mathrm{UNSTR} \\
F[1,10]=2.61^{\text {n.s. }} \\
\text { No interactions }\end{array}$ & $\begin{array}{l}5083 \text { vs. } 5062 \\
\text { ACC }=\text { UNACC } \\
F[1,10]=0.01^{\text {n.s. }}\end{array}$ & $\begin{array}{l}4946 \text { vs. } 5101 \text { vs. } 5195 \\
\text { BG }<\mathrm{WD} \\
F[2,20]=15.03^{* *}\end{array}$ \\
\hline $\begin{array}{l}\text { /d/ } \\
\quad \text { RMS burst energy (dB) }\end{array}$ & $\begin{array}{l}15.6 \text { vs. } 15.3 \\
\text { STR }=\text { UNSTR } \\
F[1,10]=0.15^{\text {n.s. }} \\
\text { STR } \times \text { ACC: } F[1,\end{array}$ & $\begin{array}{l}15.3 \text { vs. } 15.6 \\
\text { ACC }=\text { UNACC } \\
F[1,10]=0.23^{\text {n.s. }} \\
47^{*}\end{array}$ & $\begin{array}{l}15.6 \text { vs. } 15.9 \text { vs. } 14.8 \\
\mathrm{BG}=\{\mathrm{SM}>\mathrm{WD}\} \\
F[1.7,17]=4.79^{*}\end{array}$ \\
\hline $\mathrm{COG}(\mathrm{Hz})$ & $\begin{array}{l}4933 \text { vs. } 4783 \\
\text { STR }=\text { UNSTR } \\
F[1,10]=1.82^{\text {n.s. }} \\
\text { No interactions }\end{array}$ & $\begin{array}{l}4910 \text { vs. } 4805 \\
\text { ACC }=\text { UNACC } \\
F[1,10]=2.04^{\text {n.s. }}\end{array}$ & $\begin{array}{l}4890 \text { vs. } 4922 \text { vs. } 4762 \\
\mathrm{BG}=\{\mathrm{SM}>\mathrm{WD}\} \\
F[1.6,15.9]=4.7^{*}\end{array}$ \\
\hline
\end{tabular}

$* p<0.05$ and $* * p<0.01$

boundaries, but there was no difference in COG between SM boundaries and either one of the other two.

\section{3. $/ d /$}

\subsubsection{Closure duration for /d/}

As was the case for $/ \mathrm{t} /$, there were effects of all three prosodic factors on $/ \mathrm{d} /$ closure duration. Closures were longer when $/ \mathrm{d} /$ was stressed (vs. unstressed), accented (vs. unaccented) and at a stronger prosodic boundary (SM $>$ WD) (see the left side of each panel in Fig. 5). Unlike the case for $/ \mathrm{t} /$, however, there was also a Stress $\times$ Accent interaction. When stressed, accented $/ \mathrm{d} /$ was longer than unaccented $/ \mathrm{d} /\left(p<0.005, \eta^{2}=0.21\right)$. When unstressed, accented $/ \mathrm{d} / \mathrm{was}$ again longer than unaccented $/ \mathrm{d} /$, but not significantly so $\left(p=0.267, \eta^{2}=0.02\right)$. Closure durations for $/ \mathrm{d} /$ therefore show similar, but not identical prosodic strengthening patterns to those for $/ \mathrm{t} /$.

\subsubsection{Voicing duration for $/ d /$}

There were main effects of all three prosodic factors on voicing duration, but they differed in terms of directionality to some extent. Voicing duration was longer when $/ \mathrm{d} /$ was stressed (vs. unstressed) and when $/ \mathrm{d} /$ was accented (vs. unaccented), as shown in the middle of each panel in Fig. 5. But the Boundary effect had the pattern $B G<\{S M>W D\}$ (i.e., voicing duration was shorter at BG boundaries than at either of the smaller boundaries, while it was longer at SM than 


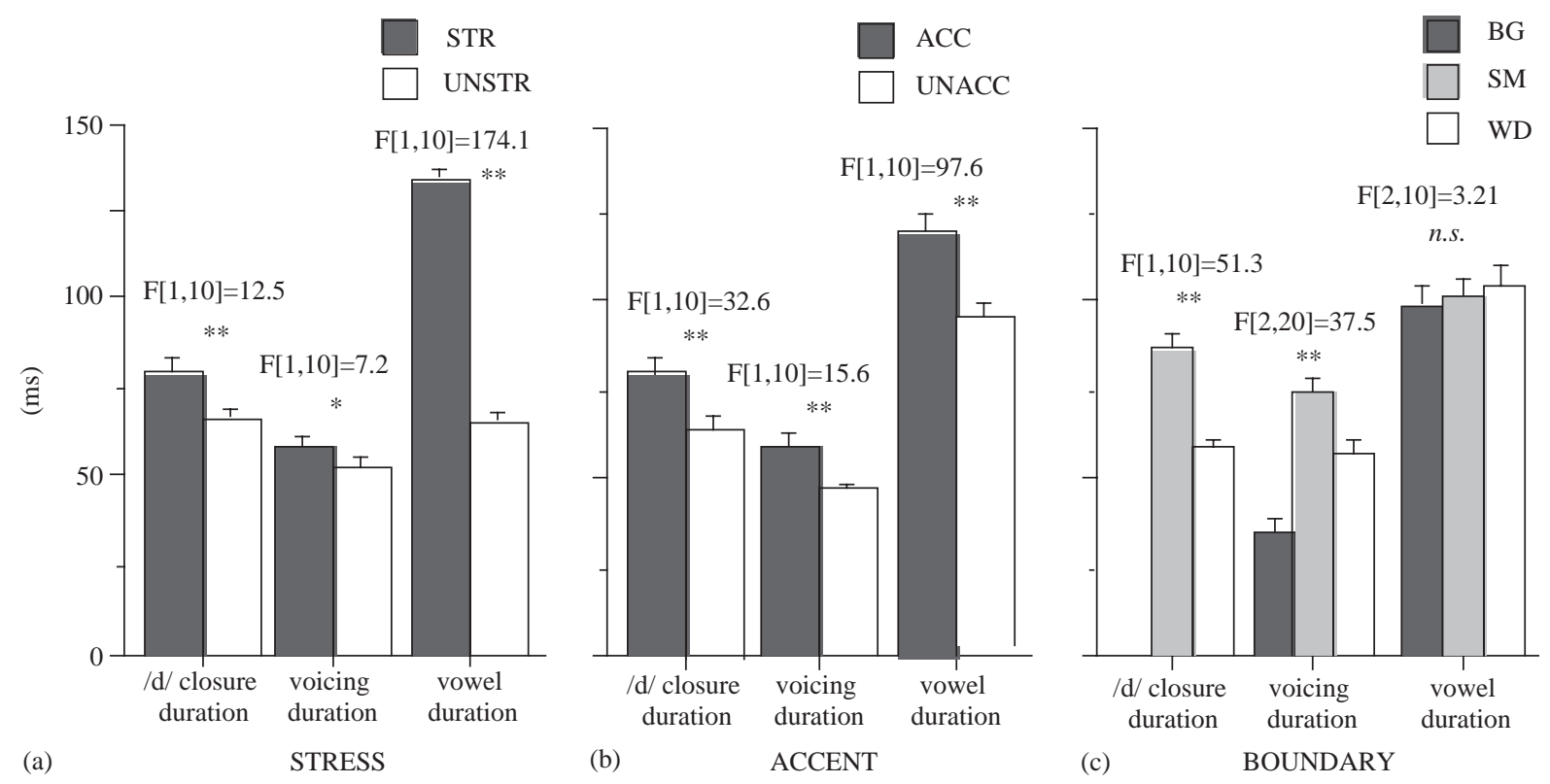

Fig. 5. /d/ closure duration, voicing duration during closure and /a/ duration in /\#da/. Error bars refer to standard errors. $* * p<0.001 ; * p<0.05$. Note that $/ \mathrm{d} /$ closure duration for $\mathrm{BG}$ was not included in ANOVAs due to the impossibility of separating the pause from the stop closure duration.

at WD boundaries). Thus, as can be seen in Fig. 5, if the BG category were excluded, voicing duration would be longer in stronger prosodic positions. There was again a Stress $\times$ Accent interaction: There was a larger effect of Accent when $/ \mathrm{d} /$ was stressed $\left(p<0.001, \eta^{2}=0.15\right)$ than when it was unstressed $\left(p=0.148, \eta^{2}=0.032\right)$.

\subsubsection{Vowel duration in $/ d a /$}

The $/ \mathrm{a} /$ in $/ \mathrm{da} /$ was significantly longer when the syllable was stressed (vs. unstressed) and accented (vs. unaccented), as shown at the right side of Figs. 5a and b. There was also a Stress $\times$ Accent interaction which was again due to a more robust accent-induced difference when the syllable was stressed $\left(p<0.0001, \eta^{2}=0.423\right)$ than when it was unstressed $(p=0.059$, $\eta^{2}=0.055$ ). Vowel duration was not influenced by Boundary size, however: There was neither a main effect of Boundary nor an interaction between Boundary and other factors. Thus, as with $/ \mathrm{t} /$ , there were clear effects of lexical stress and pitch accent, but not prosodic boundary on vowel duration.

\subsubsection{RMS burst energy for /d/}

There were no main effects of Stress and Accent on burst energy (see Table 2). These results replicate those for $/ \mathrm{t} /$. A significant Stress $\times$ Accent interaction was found, however. When the syllable was stressed, the mean burst energy was greater for accented than for unaccented $/ \mathrm{d} /$ $(15.89$ vs. $15.35 \mathrm{~dB})$, but the opposite was true $(14.82$ vs. $15.91 \mathrm{~dB})$ when the syllable was unstressed. But neither of these pairwise comparisons reached significance at $p<0.05$. In contrast 
to the results for $/ \mathrm{t} /$, there was a main effect of Boundary: Burst energy was greater for the stronger prosodic boundary SM than for the weaker WD boundary.

\subsubsection{Spectral center of gravity for /d/}

As for the burst energy measure for $/ \mathrm{d} /$, while there were no main effects of Stress and Accent, there was a main effect of Boundary on COG (see Table 2). There was a higher centroid frequency at the release for a stronger prosodic boundary $(\mathrm{SM}>\mathrm{WD})$.

\section{4. $/ s /$}

\subsubsection{Fricative duration of $/ \mathrm{s} /$}

In confirmation of the prosodic strengthening effects found for stop closure durations, there were main effects of Stress and Accent on /s/ duration. As shown in Figs. 6a and b, /s/duration was significantly longer when stressed vs. unstressed and when accented vs. unaccented. As can be seen in Fig. 6c, there was also a significant Boundary effect on /s/ duration, but the largest boundary, BG, was not associated with the longest duration. Instead, the SM boundary was associated with the longest duration, giving rise to the two-way distinction $\mathrm{SM}>\{\mathrm{BG}=\mathrm{WD}\}$, which was significant at $p<0.025$. There were no significant interactions among factors involving / s/ duration.

\subsubsection{Vowel duration in $/ \mathrm{sa} /$}

As for /s/ duration, vowel duration in /sa/ showed both Stress and Accent effects, such that vowel duration was longer for stressed than for unstressed syllables and for accented than for unaccented syllables (see Figs. 6a and b). There was, however, a significant Stress $\times$ Accent interaction $(F[1,10]=9.35, p<0.025)$, which was due to a larger Accent effect when the syllable was stressed $\left(124.5\right.$ vs. $\left.94.4 \mathrm{~ms}, p<0.0001, \eta^{2}=0.327\right)$ than when it was unstressed (57.9 vs. $\left.49.2 \mathrm{~ms}, p=0.002, \eta^{2}=0.141\right)$. There was neither a main effect of Boundary nor a significant interaction involving this factor. Vowel duration after $/ s /$ is therefore not sensitive to boundary size.
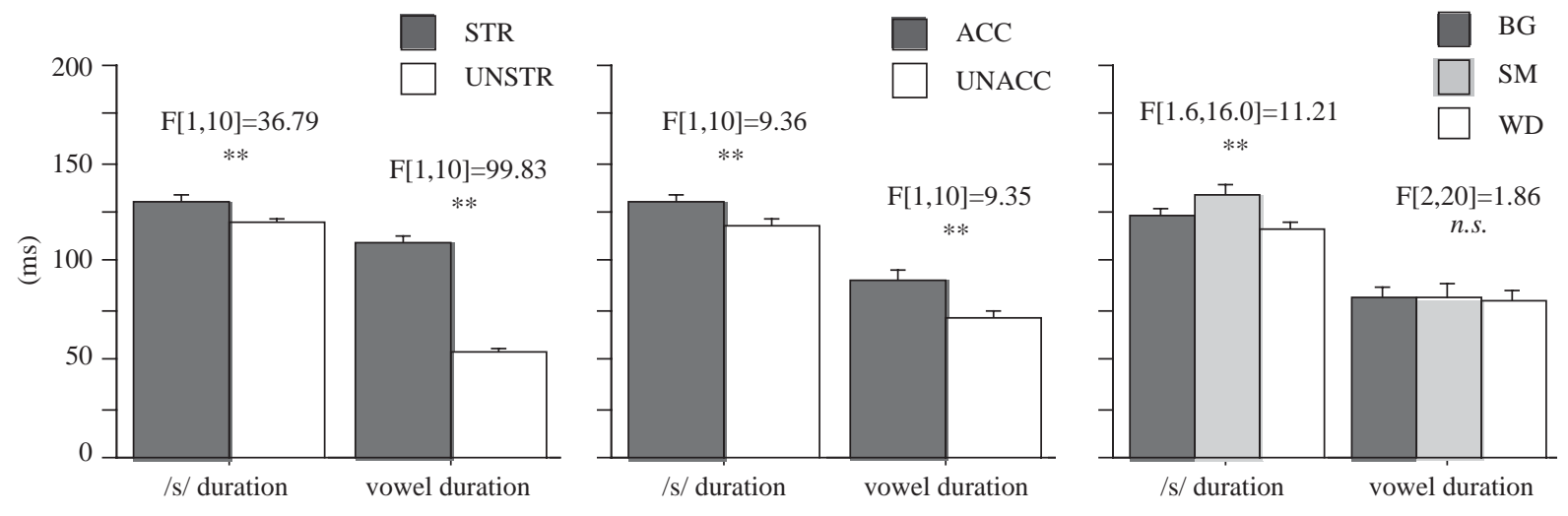

(a) STRESS

(b) ACCENT

(c)

BOUNDARY

Fig. 6. $/ \mathrm{s} /$ and $/ \mathrm{a} /$ duration in $/ \# \mathrm{sa} /$. Error bars refer to standard errors. $* * p<0.001$. 
Table 3

RMS fricative energy and spectral center of gravity for $/ \mathrm{s} /$ and $/ \mathrm{z} /$

\begin{tabular}{|c|c|c|c|}
\hline & Stress & Accent & Boundary \\
\hline \multicolumn{4}{|l|}{$|\mathrm{s}|$} \\
\hline RMS frication energy $(\mathrm{dB})$ & $\begin{array}{l}14.39 \text { vs. } 13.98 \\
\text { STR }=\text { UNSTR } \\
F[1,10]=0.712^{\text {n.s. }} \\
\text { No interactions }\end{array}$ & $\begin{array}{l}14.01 \text { vs. } 14.36 \\
\text { ACC }=\text { UNACC } \\
F[1,10]=0.674^{\text {n.s. }}\end{array}$ & $\begin{array}{l}12.58 \text { vs. } 14.15 \text { vs. } 15.82 \\
\mathrm{BG}<\mathrm{SM}<\mathrm{WD} \\
F[2,20]=30.49^{* *}\end{array}$ \\
\hline $\mathrm{COG}(\mathrm{Hz})$ & $\begin{array}{l}4991 \text { vs. } 4979 \\
\text { STR }=\text { UNSTR } \\
F[1,10]=0.028^{\text {n.s. }} \\
\text { No interactions }\end{array}$ & $\begin{array}{l}4998 \text { vs. } 4973 \\
\text { ACC }=\text { UNACC } \\
F[1,10]=0.264^{\text {n.s. }}\end{array}$ & $\begin{array}{l}4998 \text { vs. } 5035 \text { vs. } 4934 \\
\mathrm{BG}=\mathrm{SM}=\mathrm{WD} \\
F[1.5,15.4]=0.840^{\text {n.s. }}\end{array}$ \\
\hline$/ \mathrm{z} / \mathrm{RMS}$ frication energy $(\mathrm{dB})$ & $\begin{array}{l}15.11 \text { vs. } 14.48 \\
\text { STR }=\mathrm{UNSTR} \\
F[1,10]=1.425^{\text {n.s. }} \\
\text { Interaction: STR } \times\end{array}$ & $\begin{array}{l}14.76 \text { vs. } 14.83 \\
\text { ACC }=\text { UNACC } \\
F[1,10]=0.028^{\text {n.s. }} \\
F[1,10]=16.44^{* *}\end{array}$ & $\begin{array}{l}13.91 \text { vs. } 14.88 \text { vs. } 15.59 \\
\mathrm{BG}<\mathrm{WD} \\
F[1.5,15.2]=5.99^{*}\end{array}$ \\
\hline $\mathrm{COG}(\mathrm{Hz})$ & $\begin{array}{l}5003 \text { vs. } 4914 \\
\text { STR }=\text { UNSTR } \\
F[1,10]=0.882^{\text {n.s. }} \\
\text { No interactions }\end{array}$ & $\begin{array}{l}4965 \text { vs. } 4951 \\
\text { ACC }=\text { UNACC } \\
F[1,10]=0.041^{\text {n.s. }}\end{array}$ & $\begin{array}{l}5026 \text { vs. } 4992 \text { vs. } 4858 \\
\mathrm{BG}=\mathrm{SM}=\mathrm{WD} \\
F[1.4,14.1]=2.579^{\text {n.s. }}\end{array}$ \\
\hline
\end{tabular}

$* p<0.05$ and $* * p<0.01$.

\subsubsection{RMS energy for $/ s /$}

There were no effects of either Stress or Accent on frication energy (see Table 3). There was, however, an effect of Boundary, with the pattern $\mathrm{BG}<\mathrm{SM}<\mathrm{WD}$ (at $p<0.005$ ). There was thus progressively weaker RMS energy as prosodic boundaries became stronger.

\subsubsection{Spectral center of gravity for /s/}

There were no effects of Stress, Accent or Boundary on COG (see Table 3).

\section{5. $|z|$}

\subsubsection{Frication duration of $|z|$}

Both Stress and Accent had significant influence on $/ z /$ frication duration. $/ z /$ was longer when stressed than when unstressed and longer when accented than when unaccented, as shown in Figs. $7 \mathrm{a}$ and $\mathrm{b}$. Unlike /s/ duration, however, there was a significant Stress $\times$ Accent interaction $(F[1$, $10]=25.96, p<0.0001)$. This was because there was a significant accent-induced difference (ACC $>$ UNACC) when the syllable was stressed $(p<0.005, \eta=0.116)$, but not when the syllable was unstressed $\left(p=0.943, \eta^{2}=0.001\right)$. As for Boundary, $/ \mathrm{z} /$ was significantly longer at larger boundaries (BG and SM) than the smaller one (WD), as shown in Fig. 7c. There is a significant three-way (Stress $\times$ Accent $\times$ Boundary) interaction $(F[2,20]=6.589, p<0.006)$. The interaction was mainly due to the fact that for stressed and accented condition, there was a two-way 


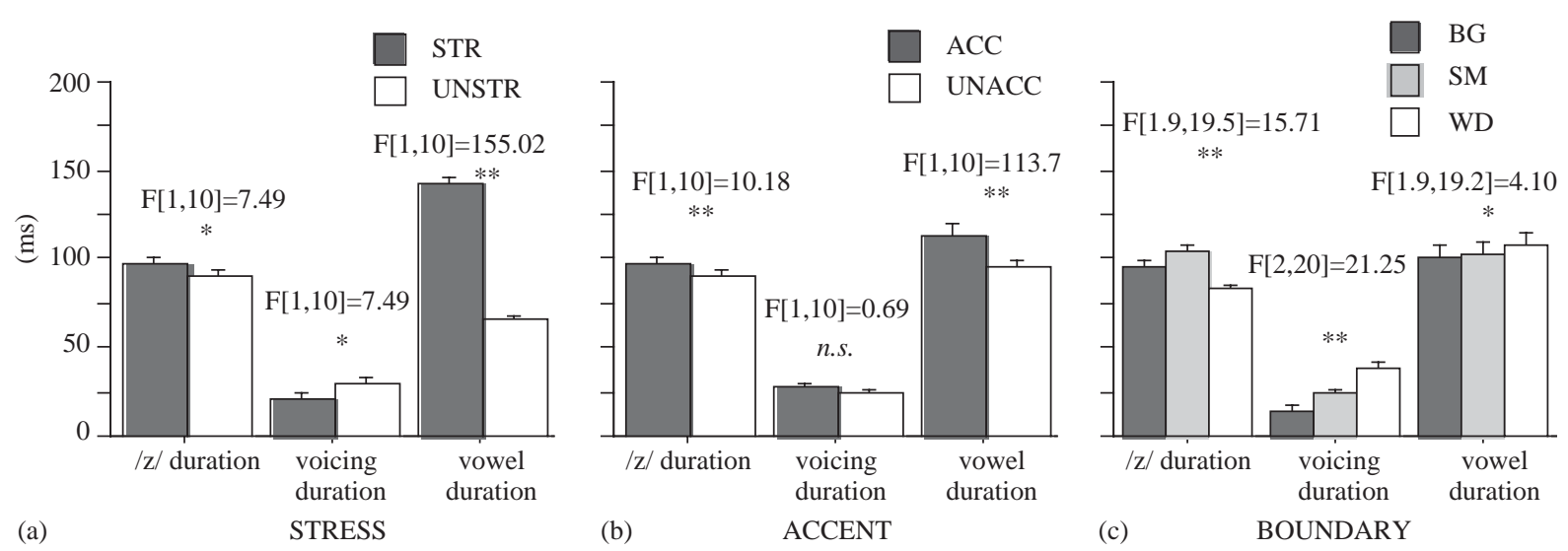

Fig. 7. $/ \mathrm{z} /$ duration, voicing during $/ \mathrm{z} /$ and $/ \mathrm{a} /$ duration in $/ \mathrm{za} /$. Error bars refer to standard errors. $* * p<0.001$; $* p<0.05$.

distinction $\{\mathrm{BG}=\mathrm{SM})>\mathrm{WD}$ whereas for all other conditions, there was a three-way distinction, $\mathrm{SM}>\mathrm{BG}>\mathrm{WD}$. The longer duration for SM than for BG was similar to the case for $/ \mathrm{s} /$.

\subsubsection{Voicing duration for $/ z /$}

As shown in the middle columns in Figs. 7a and b, there was a significant Stress effect but no Accent effect on voicing duration for $/ z /$ - voicing was significantly shorter for stressed than for unstressed /z/, while no significant difference was found between accented and unaccented /z/'s. There was no Stress $\times$ Accent interaction. There was also a main effect of Boundary on voicing duration. As shown in the middle columns of Fig. 7c, voicing duration was progressively smaller for larger prosodic boundaries, making a three-way distinction ( $\mathrm{BG}<\mathrm{SM}<\mathrm{WD}$ ), which was significant at $p<0.01$.

\subsubsection{Vowel duration in /za/}

Vowel duration was significantly longer when the syllable was stressed than when it was unstressed and significantly longer when it was accented than when it was unaccented, as shown in Figs. 7a and b (rightmost columns). There was again a significant Stress $\times$ Accent interaction, which was due to a larger Accent effect when the syllable was stressed $\left(p<0.0001, \eta^{2}=0.364\right)$ than when it was unstressed $\left(p<0.05, \eta^{2}=0.071\right)$. There was a main effect of Boundary on (postboundary) vowel duration, but none of the pairwise comparisons between prosodic levels reached significance at $p<0.05$. There was therefore only a tendency toward shorter vowel durations in postboundary /za/ at larger boundaries (see Fig. 7c).

\subsubsection{RMS energy for $/ z /$}

As was the case for $/ \mathrm{s} /$, there was no main effect of either Stress or Accent on fricative energy for $/ z /$ (see Table 3). There was, however, a Stress $\times$ Accent interaction. This was due to trends in different directions within each level of the Stress factor. RMS energy for accented $/ \mathrm{z} /$ was not significantly different from that for unaccented $/ \mathrm{z} /(15.64 \mathrm{vs} .14 .58 \mathrm{~dB} ; p=0.314)$ when the 
syllable was stressed, but the opposite was true (13.87 vs. $15.08 \mathrm{~dB}, p=0.241)$ when the syllable was unstressed. For Boundary, there was a main effect, showing smaller mean RMS energy at stronger prosodic boundary $(\mathrm{BG}<\mathrm{WD})$, as shown in Table 3 . There were no significant interactions involving the Boundary factor.

\subsubsection{Spectral center of gravity for $/ z /$}

There was neither a main effect of any prosodic factor nor an interaction between factors on COG (see Table 3).

\subsection{The Phonological Phrase boundary within the Small Phrase}

We also examined whether there was an effect of the syntactically defined PhP induced by a verb-object NP inversion within the SM category (SM; see Table 1d for an example of an utterance with a PhP boundary). Recall that SM was made up of three sentence types (PhP, List and Vocative) in different proportions (see Appendix B). Nearly 90\% of PhP sentences were grouped in SM, constituting more than half $(51.3 \%)$ of the SM category, but a smaller portion of the other sentence types were grouped in SM $(68.8 \%$ of the List sentences and $14.4 \%$ of the Vocative sentences, constituting $39.6 \%$ and $8.3 \%$ of the SM category, respectively). We thus tested whether the boundaries in PhP sentences could be differentiated from the boundaries in the other test sentences within the SM category. The tokens in the SM category were recoded into $\mathrm{SM}^{\prime}$ and PhP. SM' consisted of tokens that were not PhPs. A series of $t$-tests were then conducted on each acoustic measure. The results showed that, among the various acoustic parameters examined, two acoustic parameters showed a difference between $\mathrm{SM}^{\prime}$ and $\mathrm{PhP}$. Preboundary lengthening (CV\# duration) showed the most consistent difference across all test consonants - it was significantly longer (on the average $25.5 \mathrm{~ms}$ ) for $\mathrm{SM}^{\prime}$ than for $\mathrm{PhP}(/ \mathrm{t} /, t(81)=2.99, p<0.005$; $/ \mathrm{d} /, t(79)=2.98, p<0.005 ; / \mathrm{s} /, t(80)=2.56, p<0.01 ; / \mathrm{z} /, t(82)=3.22, p<0.0025)$. Second, stop closure duration for $/ \mathrm{t} /$ was significantly longer (on the average $15.18 \mathrm{~ms}$ ) for $\mathrm{SM}^{\prime}$ than for $\mathrm{PhP}$ $(t(81)=2.572, p<0.025)$. All other acoustic measures showed no significant differences between $\mathrm{SM}^{\prime}$ and $\mathrm{PhP}$. These findings thus suggest that speakers produce tokens of the PhP differently from other tokens in the category of SM.

\section{Summary and discussion}

The main purpose of the present study was to investigate the effects of the three prosodic factors lexical stress, accent and prosodic boundary on the production of the consonants $/ \mathrm{t} \mathrm{d} \mathrm{s} \mathrm{z/}$ in Dutch. The results can be summarized as follows:

a. All test consonants were produced with longer duration (stop closure or frication) both in stressed and accented syllables. The boundary effect on consonant duration was also observed for both stops and fricatives, showing at least a two-way distinction when considering only SM and WD (BG items were excluded from the stop closure analysis because of the pause). That is, stop closure and frication duration were longer at stronger prosodic boundaries (SM $>$ WD). For $/ \mathrm{s} /$, however, there was no significant difference between BG and either SM or WD, but for 
$/ z /$, a three-way distinction $(\mathrm{SM}>\mathrm{BG}>\mathrm{WD}$ ) was found for all conditions other than the stressed and accented condition. The shorter duration of $/ \mathrm{z} /$ for BG than for SM and the lack of difference between BG and smaller boundaries for /s/ appear to run counter to the general initial strengthening pattern. Shortened frication duration after a pause, however, may be due to the extra time required to set the appropriate aerodynamic and articulatory conditions needed for producing frication after a pause. This effect may be even stronger when voicing (i.e., for $/ z /$ ) is involved (Lisker \& Abramson, 1964; Fougeron, 2001).

b. For voicing-related measures, /t/ showed shorter VOTs and /d/ showed longer voicing duration during closure in prosodically stronger locations (stressed vs. unstressed syllables, accented vs. unaccented syllables, at higher vs. lower prosodic boundaries). One exception to this general pattern was that for $/ \mathrm{d} /$, although voicing duration was longer for SM than for WD, it was significantly shorter for BG than for both SM and WD. Again, the initiation of voicing after a pause might require more time for aerodynamic reasons, which is why shortened voicing durations are often observed (see Fougeron, 2001).

c. Voicing duration during /z/ showed significant effects of lexical stress and prosodic boundary, but not of accent. It was shorter in stressed than unstressed syllables and shorter at higher prosodic boundaries, showing a significant three-way distinction $(\mathrm{BG}<\mathrm{SM}<\mathrm{WD})$.

d. Vowel duration in \#CV was significantly affected by lexical stress and pitch accent, showing a robust lengthening effect in stronger prosodic positions. However, it was not sensitive to prosodic boundary strength, except for one case in which /a/ in unstressed $/ \mathrm{ta} /$ was longer after a BG than a WD boundary.

e. RMS burst energy for $/ \mathrm{t} d /$ did not reliably mark either stressed or accented syllables for both $/ \mathrm{t}$ $\mathrm{d} /$, nor the boundary strength for $/ \mathrm{t} /$. The only significant effect found was for $/ \mathrm{d} /$, which showed significantly higher RMS burst energy for SM than for WD.

f. RMS spectral energy for $/ \mathrm{s} \mathrm{z/}$ showed no effect of stress and accent. However, there was a significant boundary effect showing lower RMS spectral energy for both $/ \mathrm{s} /$ and $/ \mathrm{z} /$ at higher prosodic boundaries.

g. Spectral COG at the stop release was not a reliable phonetic correlate of stress and accent. On the other hand, it was significantly influenced by the boundary factor, but in an inconsistent fashion between $/ \mathrm{t} /$ and $/ \mathrm{d} /$. For $/ \mathrm{t} /$, it was significantly lower at a higher prosodic boundary (BG) than at a lower one (WD), whereas for $/ \mathrm{d} /$, it was higher at a higher prosodic boundary (SM) than at a lower one (WD).

\subsection{Prosodic strengthening and phonetic correlates}

These results show that consonants are produced differently in different prosodic locations, which suggests that prosodic structure is signaled by systematicities that may be found in finegrained phonetic details. In particular, the duration of consonants is generally longer in stressed and accented syllables and at the beginning of larger prosodic constituents. This prosodically conditioned lengthening effect will be referred to as 'prosodic lengthening'. These findings are compatible with previous studies on prosodically conditioned lengthening/strengthening effects in other languages (Lehiste, 1970; Cambier-Langeveld \& Turk, 1999; Cho \& Keating, 2001; Fougeron, 2001; Cho, 2002, in press; Tabain, 2003a, b; Keating et al., 2003, among others). Note that although Fougeron (2001) found inconsistent patterns of prosodic lengthening in 
French fricatives, Kim (2001, in press) has found more consistent patterns in Korean fricatives. Given that the longer closure duration of lingual (coronal) consonants in prosodically stronger locations is generally associated with more extreme articulation, as reflected in more linguopalatal contact especially for stops (Cho \& Keating, 2001; Fougeron, 2001), the observed prosodic lengthening may well be related to prosodically conditioned articulatory strengthening.

The pattern of prosodic lengthening, however, was inconsistent in the measurements of vowel duration in \#CV. While prosodic lengthening was still observed in the vowels of stressed and accented syllables, the boundary-induced prosodic lengthening effect disappeared. This suggests that the domain of prosodic lengthening differs depending on the type of prosodic location: the postboundary prosodic lengthening effect is largely restricted to the first segment (this time, the onset consonant) of the postboundary syllable, as opposed to stress- and accent-induced prosodic lengthening, which is in general observed in both the consonant and the vowel. Byrd and Saltzman explain the locality of the boundary-induced effect in the framework of a mass-spring gestural model (Byrd, 2000; Byrd \& Saltzman, 2003). They hypothesize that articulation at the edges of prosodic constituents is governed by an abstract nontract variable prosodic boundary gesture (' $\pi$-gesture'), whose domain of influence is local to the edges of prosodic domains-i.e., "only the constriction gestures within the $\pi$-gesture's temporal field of activation are directly affected, not gestures remote from the phrasal boundary" (Byrd, 2000, p. 14). A computational simulation with a clock-slowing implementation (Byrd \& Saltzman, 2003) showed that, for the sequence $C_{1} V_{1} \# C_{2} V_{2}$, the articulations that are closest to the prosodic boundary are the most influenced by the $\pi$-gesture, and thus show the strongest lengthening effect. In contrast, stress- and accent-induced lengthening effects are not local to initial consonants because they may be determined by specific dynamical parameters such as gestural stiffness and magnitude activated over both consonantal and vocalic articulations (see Edwards et al., 1991; Harrington, Fletcher, \& Roberts, 1995, for dynamic accounts of accent-induced lengthening).

In addition to the robust prosodic lengthening effects, other acoustic measures, such as VOT for $/ \mathrm{t} /$ and voicing duration for $/ \mathrm{d} /$ and $/ \mathrm{z} /$, also showed consistent prosodic effects (see Section 4.4 for further discussion on the voicing contrast). Yet other measures, however, produced rather inconsistent prosodic effects. RMS burst energy for stops is expected to vary if degree of oral pressure behind the oral constriction and/or the degree of the speed of the release changes as a function of prosodic factors (Cho \& Keating, 2001). The present results, however, have shown that RMS stop burst energy is not a reliable phonetic parameter that varies as a function of prosodic position. This is further confirmed by poor correlations between consonant duration (the most reliable phonetic correlate) and RMS burst energy $(/ \mathrm{t} /, r=0.083 ; / \mathrm{d} /, r=0.088)$. At first glance, these results are somewhat different from those of Cho and Keating (2001), where it was shown that RMS burst energy for Korean, especially in voiceless 'aspirated' stops, was a reliable phonetic cue to prosodic boundary strength (though note that this effect was not as strong as that on consonant duration). Such a cross-linguistic difference in stop burst energy appears to be related to the characteristics of aspirated and unaspirated stops. Cho and Keating showed that Korean lenis stops (less aspirated stops), like the Dutch voiceless stops examined here, showed no consistent burst energy variation as a function of boundary strength.

There was also no consistent prosodic effect on COG at the stop release. While COG at the stop release was not significantly influenced by the stress and accent factors, the boundary effect showed opposite patterns for $/ \mathrm{t} /$ and $/ \mathrm{d} /$. For $/ \mathrm{t} /$, it was significantly lower at a higher prosodic 
boundary (BG) than at a lower one (WD), whereas for $/ \mathrm{d} /$, it was higher at a higher prosodic boundary (SM) than at a lower one (WD). One assumption was that (prosodically conditioned) variation in the linguopalatal contact area for stops could result in a change in the size of the front cavity, and, therefore, in the front cavity resonance. This could have been reflected in the COG measure (Forrest et al., 1988; Zsiga, 1993; Harrington \& Cassidy, 1999). However, the fact that the COG effect for $/ \mathrm{t} /$ went in the opposite direction to that for $/ \mathrm{d} /$ makes it hard to interpret these data.

It might be possible to reconcile the apparently contradictory results for $/ \mathrm{t} / \mathrm{and} / \mathrm{d} /$, however, if we consider a potential difference in place of articulation between $/ t /$ and $/ d /$. Van Alphen and Smits (2004) have shown that, for word-initial stops in Dutch spoken in isolation, /d/ is generally produced with a lower COG than $/ t /$. The same pattern was also observed here (see Table 2). Van Alphen and Smits suggest that the place of articulation for $/ \mathrm{d} /$ may be somewhat more posterior than that for $/ \mathrm{t} /$. The different effects of prosodic structure on COG between $/ \mathrm{t} /$ and $/ \mathrm{d} /$ found in the present study might reflect this hypothetical difference in place of articulation. At a stronger boundary (as for words in isolation), / $t$ / was produced with a lower COG than at a weaker boundary, and /d/ was produced with a higher COG at a stronger boundary (again, as in isolation). Thus, one might speculate that the observed COG differences in the present study mark boundary strength, such that the place of articulation difference between $/ \mathrm{t} /$ and $/ \mathrm{d} /$ is emphasized. Further articulatory studies will certainly be necessary to test this speculation. Nevertheless, whatever the source of the effect might be, COG appears to mark boundary strength to some extent, though differently for $/ \mathrm{t} /$ than for $/ \mathrm{d} /$.

With respect to fricatives, RMS spectral energy and COG also turned out to be generally insensitive to stress and accent factors. Again, there were no strong correlations either between consonant duration and RMS spectral energy $(/ \mathrm{s} /, r=0.012 ; / \mathrm{z} /, r=0.127)$, or between duration and $\operatorname{COG}(/ \mathrm{s} /, r=0.17 ; / \mathrm{z} /, r=0.23)$. There was a significant boundary effect on RMS spectral energy, however, for both $/ \mathrm{s} /$ and $/ \mathrm{z} /$. RMS energy was lower at a higher prosodic boundary. One might expect higher RMS energy at a higher prosodic boundary, making the sound louder. But in order to understand the mechanisms for variation in frication energy, we need to understand exactly how the two sources of the noise, oral constriction degree and glottal constriction degree, interact. Furthermore, the relative level of amplitude for frication noise is not linearly correlated with the constriction degree (Stevens, 1999, p. 109) - the energy level increases initially as the constriction degree increases but it decreases after the constriction degree reaches a certain threshold. It may thus be the case that the lower RMS energy at higher boundaries may after all reflect articulatory strengthening: A greater oral constriction could result in a weaker frication noise. Again, while more articulatory studies need to be done to corroborate this possibility, what is certainly clear is that prosodic boundary strength is marked by RMS spectral energy.

\subsection{Interactions between prosodic factors}

\subsubsection{Stress $\times$ Boundary interactions}

One of the specific objectives of the present study was to examine whether and how the effects of lexical stress, pitch accent and intonational boundary interact with each other in determining consonant production. Let us first consider the Stress $\times$ Boundary interaction. We found that there were no significant interactions between these two factors for all consonants except $/ \mathrm{t} /$. 
These results indicate that boundary-induced phonetic effects for the three consonants $/ \mathrm{d}, \mathrm{s}, \mathrm{z} /$, when present, are generally consistent across stressed and unstressed initial syllables, suggesting some degree of generality of the boundary effects.

In contrast, for $/ t /$, there were significant Stress $\times$ Boundary interactions in VOT and vowel duration. In the VOT analysis, the boundary effect was stronger when $/ t /$ was unstressed than when it was stressed. One possible explanation for this finding is that it is due to a floor effect: VOT was already shortened in the stressed syllable, leaving little room for further shortening, but in the unstressed syllable there was less shortening, so boundary-induced VOT shortening may have been possible. Similarly, though in an opposite direction, vowel duration for /ta/ was already lengthened in stressed syllables (so there was no further lengthening coming from boundary strength), but when /ta/ was unstressed, there may have been no such ceiling effect. (See CambierLangeveld, 1999, 2000 for a similar ceiling effect in the interaction between preboundary lengthening and accentual lengthening in Dutch.) An interesting fact, however, is that the boundary effect on vowel duration (when unstressed) was observed only for $/ t /$. The boundaryinduced vowel lengthening for /ta/ may then be a compensatory effect coming from shortened VOT at stronger prosodic boundaries. There was indeed a significant negative correlation between VOT and vowel duration when $/ \mathrm{ta} /$ was unstressed $(r=-0.469)$, but not when $/ \mathrm{ta} /$ was stressed $(r=-0.126)$.

\subsubsection{Stress $\times$ Accent interaction}

Another question with respect to between-factor interactions was whether the effect of accent would be limited to stressed initial syllables. Stress $\times$ Accent interactions were found in several phonetic measures: /d/ and /z/ consonant duration, /d/ voicing duration, RMS spectral energy for $\mid z /$, and vowel duration for all test consonants. These interactions were mainly due to the fact that the effect of accent was more robust when the syllable was stressed than when it was unstressed (as suggested by $\eta^{2}$ statistics). However, while such interactions suggest that accentuation is phonetically realized on stressed initial syllables to a greater extent than on unstressed initial syllables, there were other cases with no such interactions. For example, /t/ stop closure and $/ \mathrm{s} /$ frication duration both showed significant lengthening effects of accent regardless of whether the initial $/ \mathrm{t} /$ and $/ \mathrm{s} /$ occurred in stressed or unstressed syllables. Furthermore, even in a case like vowel duration which showed a significant Stress $\times$ Accent interaction, the effect of accent was significant for both stressed and unstressed syllables. Thus, although the accent effect was more robust on stressed initial syllables than on unstressed ones, it was certainly not limited to stressed initial syllables.

The finding that accent influences consonantal realization in unstressed syllables has implications for the theory of the domain of accentual lengthening. Several phonetic studies have examined accentual lengthening phenomena (i.e., lengthening due to accent; Eefting, 1991; Turk \& Sawusch, 1997; Cambier-Langeveld \& Turk, 1999; Turk \& White, 1999; CambierLangeveld, 1999, 2000, among others). The question addressed in such studies is whether the domain of accentual lengthening is limited to or bounded by a certain linguistic unit such as the stressed syllable, the foot within the word, or to a domain larger than a foot (e.g., the Prosodic Word). This question has been addressed by examining whether the lengthening effect, which is present predominantly on lexically stressed syllables within the accented word, also spreads leftward or rightward or in both directions to unstressed syllables. Earlier work on this issue in 
American English (Turk \& Sawusch, 1997) suggested that the domain of accentual lengthening includes the accented stressed syllable and at least one following unstressed syllable (i.e., a rightward effect), i.e., a domain which corresponds roughly to the foot. A subsequent study (Turk \& White, 1999), however, suggested that there is also a small but significant leftward effect (i.e., the unstressed syllable before the accented syllable is also lengthened), though the leftward effect was smaller than the rightward effect.

The present study in Dutch has shown clear accent-induced lengthening on unstressed syllables to the left of the stressed syllable within the accented word, in both consonant and vowel duration in \#CV, as has previously been shown in other studies on Dutch (e.g., Eefting, 1991; Nooteboom, 1972). This finding confirms that the domain of accentual lengthening in Dutch is indeed not limited to the foot, which groups the stressed syllable with subsequent unstressed syllables but not with preceding unstressed syllables.

Another relevant finding was that the accentual lengthening effect did not interact with prosodic boundary type, indicating that accentual lengthening is independent of the size of the prosodic boundary. As pointed out by Cambier-Langeveld and Turk (1999), given that the leftward accentual lengthening found in their study (and the present experiment) was always on word-initial unstressed syllables, it is difficult to disentangle lengthening due to word-initial position from accentual lengthening. Nevertheless, the fact that the leftward accentual lengthening effect was independent of the size of the prosodic boundary, and the fact that there were accent effects on unstressed syllables do indicate that the lengthening effect was not entirely a positional effect. Thus, however small the leftward effect might be as compared to the rightward effect, it appears to be due at least in part to accentuation (but note that in the present study we were unable to compare the amount of accentual lengthening in leftward and rightward directions).

\subsection{Phonetic evidence for an intermediate phrase level}

We also examined whether the tokens of the syntactically defined $\mathrm{PhP}$ (see Table 1) within the SM could be differentiated from the other SM tokens. The SM was defined based on two broad phonetic criteria - the presence of a boundary tone and no pause. Sentences belonging to the SM category could be divided into two, however, if one were to adopt a model of prosodic organization such as that of Beckman and Pierrehumbert (1986, see also Beckman \& Elam, 1997) in which the Intonational Phrase and the Intermediate Phrase are differentiated by intonational and temporal characteristics at the end of the prosodic constituents. In this particular model, a pause is not a necessary feature of an Intonational Phrase boundary. The boundaries in the SM category could therefore reflect either Intonational or Intermediate Phrases. (Note also that the boundaries of all sentences in the BG category are most likely to reflect Intonational Phrases in this framework.) It is beyond the scope of this study to categorize all the utterances in the recording sample according to the definitions in this particular model. Nevertheless, we were able to find phonetic evidence that distinguished among subsets of utterances in the SM category.

Preboundary lengthening clearly separated PhP utterances from the other SMs - preboundary syllable duration was significantly shorter for $\mathrm{PhP}$ than for $\mathrm{SM}^{\prime}$ in all four postboundary consonant conditions. This result is in line with Hofhuis et al. (1995), who showed in Dutch syllables which were closed with nasals or liquids that some preboundary lengthening effects at 
PhP boundaries were differentiated from lengthening effects at Prosodic Word and Utterance boundaries. (But see Cambier-Langeveld, 2000, in which a PhP boundary falling between a verb and a complex object NP, a syntactic structure different from the one in the present study, did not induce preboundary lengthening.) A $\mathrm{PhP}$ effect was also evident in the present study in the pattern of postboundary $/ \mathrm{t} /$ stop closure duration - stop closures for $/ \mathrm{t} /$ was significantly shorter for $\mathrm{PhP}$ than for $\mathrm{SM}^{\prime}$ tokens, although there were no $\mathrm{PhP}$ effects on the production of the other postboundary consonants / $\mathrm{d} \mathrm{z} /$.

Given that preboundary lengthening has been one of the major cues to prosodic boundary strength cross-linguistically, one could interpret the results as suggesting that there is an intermediate-level phrase in Dutch, which cannot be simply defined by the presence or absence of a boundary tone and by the presence or absence of a pause. Booij (1995, p. 146) notes that "[f]or Dutch, the issue of the prosodic domains of [phonological] rules above the level of the Prosodic Word is an underresearched area". Although the present study does not test prosodic constituents as domains of phonological rules, the demonstration that some phonetic cues are associated with the $\mathrm{PhP}$ increases the likelihood of the PhP (or the Intermediate Phrase, if one prefers) as a viable prosodic constituent in the prosodic hierarchy of Dutch.

The fact that the phonetic evidence for an intermediate-level phrase comes from the syntactically defined PhP confirms the close relationship between syntax and prosodic structure. This is not to argue, however, that $\mathrm{PhP}$ sentences are the only sentence type that represents the intermediate-level phrase, but to point out that a certain syntactic structure (verb-object NP inversion) appears to be produced more often with a particular prosodic phrasing. It is clear that syntactic influences on prosodic realization can be overridden by constraints such as speech rate, length and communicative intent (Nespor \& Vogel, 1986; Jun, 1993; Keating \& ShattuckHufnagel, 2003). In fact, we observed that some of the $\mathrm{PhP}$ sentences $(10.8 \%)$ were indeed grouped in the BG and WD categories, suggesting that some sort of restructuring can take place in the production process of $\mathrm{PhP}$ sentences. Further research will therefore be required to establish not only the phonological and phonetic status of intermediate-level phrases in Dutch but also the degree to which such phrases are determined by syntactic vs. other factors.

\subsection{Language-specificity and contrast enhancement}

We have found that stop consonants are in general more strongly articulated in prosodically strong locations. This was evident primarily in lengthening effects. These results are compatible with prosodically conditioned strengthening phenomena that have previously been reported in other languages, including English, especially in terms of the strengthening of domain-initial stops as compared to domain-medial ones (Fougeron \& Keating, 1997; Fougeron, 2001; Cho \& Keating, 2001; Cho, 2002, in press). Where Dutch appears to diverge from English, however, is in the variation of VOT as a function of prosodic structure. English voiceless stops are generally produced with longer VOTs in prosodically stronger locations, and this has been taken to be one of the most robust phonetic cues of stress, accent and prosodic boundary that is associated with voiceless stop consonants (Lisker \& Abramson, 1967; Cooper, 1991; Pierrehumbert \& Talkin, 1992; Choi, 2003; Cole et al., 2003, among others). The longer VOT in prosodically stronger locations can be interpreted as a result of articulatory strengthening of the glottal abduction (opening) gesture associated with voiceless stops (Cooper, 1991; Pierrehumbert \& Talkin, 1992; 
Cho \& Keating, 2001). The prosodic lengthening of VOT in English for $/ \mathrm{t} / \mathrm{can}$ thus be interpreted as resulting in enhancing contrast between $/ \mathrm{t} /$ and $/ \mathrm{d} /$.

The present study has shown, however, that the voiceless stop / $\mathrm{t} /$ in Dutch is produced with shorter VOT in all prosodically strong locations. This prosodic shortening leads to a question about the relationship between prosodically conditioned strengthening and contrast between $/ \mathrm{t} /$ and $/ \mathrm{d} /$ - i.e., whether the hyperarticulation associated with prosodically strong locations may result in an enhancement of paradigmatic contrast, i.e., an enhancement of distinctive features in ways that maximize lexical contrast, as proposed by de Jong (1995; see also Cho, 2005, for further discussion of prosodically conditioned enhancement of distinctive features for vowels).

Assessment of the degree of voicing contrast between $/ \mathrm{t} /$ and $/ \mathrm{d} /$ can be made by looking at the distribution of both voicing lead (voicing during closure) and voicing lag (VOT) values associated with the contrastive stops, as was elaborated in Keating's (1984a) polarization hypothesis (cf. Hsu \& Jun, 1998). The polarization hypothesis was derived from cross-linguistic observations of voicing contrast in stops. First, it was proposed that three and only three phonetic categories are needed in order to account for the phonological contrast between stops in the world's languages: \{voiced\}, \{voiceless unaspirated\} and \{voiceless aspirated\}. Second, when there is a two-way voicing distinction in a given language, the distinction is made along the voicing dimension between two adjacent categories. Third, and most crucially, the polarization principle predicts that within these chosen phonetic categories, the distributions of values are maximally separated. The polarization hypothesis is rooted in Dispersion Theory (Liljencrants \& Lindblom, 1972; Lindblom, 1986, 1990), but differs in that it restricts the domain of maximal dispersion to that within the chosen adjacent categories in a given language. Note, however, that Cho and Ladefoged (1999) and Ladefoged and Cho (2001) have argued for arbitrariness in certain languages in the choice of VOT values. That is, the choice of VOT values in a given language does not necessarily depend on the phonological opposition in that language, such that the opposition between voiced and voiceless consonants can be made using nonadjacent voicing categories. Nevertheless, enhancement of the contrast between $/ \mathrm{t} /$ and $/ \mathrm{d} /$ in Dutch could be achieved by increased polarization of the two contrastive stops on the VOT continuum between the two adjacent voicing categories (\{voiced $\}$ and \{voiceless unaspirated\})-i.e., more extreme prevoicing for $/ \mathrm{d} /$ and more extreme positive VOT for $/ \mathrm{t} /$ in prosodically stronger locations.

It was indeed the case that $/ \mathrm{d} /$ was produced with more prevoicing in stressed and accented syllables, and also that there was more voicing for $/ \mathrm{d} /$ at the beginning of the SM than at the beginning of the Prosodic Word. While this increased amount of prevoicing for $/ \mathrm{d} /$ can be interpreted as an enhancement of the voicing contrast (presumably via stronger implementation of the phonetic feature $\{+$ slack vocal folds $\}$ ), the decreased VOT for $/ \mathrm{t} /$ in prosodically stronger positions appears to reduce the voicing contrast. Thus, to the extent that the VOT dimension is considered, contrast enhancement between $/ \mathrm{t} /$ and $/ \mathrm{d} /$ was not transparently evident in the present Dutch data. That is, these results do not fully support the polarization hypothesis.

The VOT results can, however, be explained in terms of phonetic feature enhancement if crosslinguistic differences in phonetic features are taken into account. As we pointed out in Section 1, there is an important cross-linguistic difference between English and Dutch stops. Both languages have a two-way phonological contrast in stops (voiced vs. voiceless). In order to maintain such a phonological contrast, we may only need the phonological feature [ \pm voice] for both languages (Kingston \& Diehl, 1994). Nevertheless, Dutch voiceless stops are generally produced with shorter 
VOTs (less aspiration) than English ones, all else being equal. As Keating (1984a, 1990) proposed, a secondary phonetic feature is necessary to account for this kind of cross-linguistic variation (see also Keating, 1990; Cohn, 1993, for discussion on the phonetic component in the grammar). Following Keating (1990), we proposed the phonetic feature $\{ \pm$ spread glottis $\}$ for [-voice] stops: English voiceless stops have the feature $\{+$ spread glottis $\}$; and Dutch voiceless stops have $\{-$ spread glottis $\}$.

These assumptions can account not only for the overall cross-linguistic aspiration difference between English and Dutch /t/'s, but also for the cross-linguistic difference in prosodically conditioned strengthening patterns. In English, strengthening of voiceless stops could therefore be reflected in the enhancement of the language-specific phonetic feature $\{+$ spread glottis $\}$. If this feature were phonetically implemented by a glottal abduction (opening) gesture, this would result in relatively long VOTs (as in the language as a whole, relative to Dutch), and lengthening of VOT when the feature was enhanced. In Dutch, strengthening of voiceless stops could in contrast involve enhancement of the feature $\{-$ spread glottis $\}$. If this were implemented by a glottal adduction (closing) gesture, this would result in relatively short VOTs, and shortening of VOT when the feature was enhanced. The VOT results thus suggest that the enhancement of the phonological distinction between $/ \mathrm{t} /$ and $/ \mathrm{d} /$ appears to be modulated not simply by the principle of contrast maximization along the phonetic dimension (i.e., the polarization hypothesis), but also by the language-specific system of phonetic components in the grammar in which phonetic features are specified with phonetic content. Prosodic strengthening therefore appears to operate primarily at the phonetic level, such that prosodically driven enhancement of phonological contrast is determined by how (language-specific) phonetic features are implemented.

A related contrast pattern was that while voicing duration was longer in prosodically stronger locations for $/ \mathrm{d} /$ (except for BG vs. SM), the opposite was true for $/ \mathrm{z} /$. There was increased phonetic devoicing of $/ z /$ in stressed syllables and at higher prosodic boundaries. This is odd, especially given that maintaining voicing during the stop closure $(/ \mathrm{d} /)$ is generally harder than during frication $(/ \mathrm{z} /)$. A transglottal air pressure difference (oral air pressure $\left(P_{\mathrm{o}}\right)<\operatorname{subglottal}$ air pressure $\left.\left(P_{\mathrm{s}}\right)\right)$ is required for voicing. Initiating or maintaining this difference is more difficult for / $\mathrm{d} /$ than $/ \mathrm{z} /$. This is because the closed air pathways during the stop closure cause $P_{\mathrm{o}}$ to approach $P_{\mathrm{s}}$. Other active articulatory actions such as expansion of the vocal track wall and/or lowering of the larynx during the stop closure can, however, help to maintain the pressure difference (Ohala, 1983; Westbury, 1983; Westbury \& Keating, 1986).

The question then is why speakers make more effort to make /d/ more voiced in prosodically stronger locations, but do not do so for $/ \mathrm{z} /$. One possible explanation is that for the $/ \mathrm{t} /-/ \mathrm{d} /$ contrast, since VOT shortening for $/ \mathrm{t} /$ does not increase the phonetic contrast along the voicing dimension between $/ \mathrm{t} /$ and $/ \mathrm{d} /$, speakers may compensate for it by making extra effort to maintain voicing for $/ \mathrm{d} /$. An alternative or additional explanation is that the phonemic status of $/ \mathrm{z} /$ in Dutch is not the same as $/ \mathrm{d} /$. There are fewer minimal pairs for $/ \mathrm{s} / \mathrm{vs}$. $/ \mathrm{z} /$ than for $/ \mathrm{t} / \mathrm{vs}$. $/ \mathrm{d} /$. A search of the CELEX lexical database for Dutch (Baayen, Piepenbrock, \& Rijn, 1993) found 98 minimal pairs differing only in $/ \mathrm{s} /-\mathrm{z} /$ in word-initial position (these words had a mean frequency of occurrence of 68 per million words), and 389 equivalent minimal pairs for $/ \mathrm{t} /-\mathrm{d} /$ (with a mean frequency of 128 per million). Furthermore, many Dutch speakers do not maintain the $/ \mathrm{s} /-/ \mathrm{z} /$ distinction in initial position (Ernestus, 2000). If $/ \mathrm{z} /$ therefore has a relatively weak phonemic status, then this may be why the voicing contrast between $/ \mathrm{s} /$ and $/ \mathrm{z} /$ was not enhanced by increased voicing for $/ z /$ in prosodically stronger locations. 


\subsection{Conclusions}

The present study investigated prosodic influences on phonetic realizations of four Dutch consonants (/t d s z/) by examining the prosodic factors lexical stress, phrasal accent and prosodic boundary. As evident in various acoustic measurements, phonetic realizations of individual segments varied systematically with prosodic factors. This indicates that low-level phonetic implementation is influenced by prosodic structure. The prosodically driven fine-grained phonetic detail that is thus present in the speech signal may be used by listeners during speech comprehension. Listeners may marshall all of this evidence for prosodic structure as they process continuous speech. It has been argued, e.g., that prosody is used by listeners to help retrieve the syntactic structure of utterances (e.g., Schafer, 1997; Kjelgaard \& Speer, 1999; Carlson, Clifton, \& Frazier, 2001; Jun, 2003) and to help in word recognition (e.g., Kim, 2003, 2004a, b). Information specifying the location of prosodic boundaries may also be used by listeners to help resolve lexical ambiguities in the segmentation of continuous speech (Salverda, Dahan, \& McQueen, 2003). Recent research has been aimed specifically at the role of domain-initial consonantal strengthening in lexical segmentation in English (McQueen \& Cho, 2003; Cho, McQueen, \& Cox, submitted). This research suggested that the difference between the initial CV of a word spoken at an Intonational Phrase boundary and the same CV taken from a phrase-medial word can be used by listeners in word recognition. It is hoped that the present study will serve as a basis to explore further the role of prosody in speech comprehension, especially with respect to the role of prosodic strengthening in the process of continuous speech recognition in Dutch.

Our results lead to a number of conclusions about prosodic influences on consonant production. The boundary effect on domain-initial segments was found in both stressed and unstressed initial syllables. This suggests that domain-initial strengthening is a general phenomenon. This in turn suggests that cues to prosodic structure in the speech signal are not limited to certain words (i.e., words with stressed initial syllables) and thus may be of more value to listeners. The accentual effect was not limited to stressed syllables but extended to unstressed initial syllables. This indicates that the domain of accentuation in Dutch is at least larger than the foot. Furthermore, this effect was independent of prosodic boundary size. These results imply that prosodic structure influences the realization of segments at a number of different levels of processing.

Finally, our results suggest that there are cross-linguistic differences in the prosodic modulation of segment realization. Based on the language-specific pattern we observed in the phonetic realization of the voicing contrast (e.g., shortened VOT in Dutch voiceless stops vs. lengthened VOT in English voiceless stops in stronger prosodic positions), we proposed that the phonetics-prosody interface is modulated by the language-specific phonetic component of the grammar in which phonetic features (e.g., $\{ \pm$ spread glottis $\}$ ) are specified with phonetic content. Prosodic structure in a given language thus appears to influence the realization of the phonetic information that is relevant for lexical distinctions in that language.

\section{Acknowledgements}

This research was supported in its entirety by the Max Planck Society and was conducted when the first author was at the Max Planck Institute for Psycholinguistics, Nijmegen, The Netherlands. We thank Carlos Gussenhoven for valuable discussions and for his help with constructing the 
sentences. Special thanks goes to Tau van Dijck, Marloes van der Goot, Loulou Edelman and Manon van Laer for their help at various stages of the study including prosodic transcription, material construction and data collection. We also thank the Comprehension Group at the MPI for Psycholinguistics, especially Anne Cutler, Roel Smits, Petra van Alphen and Mirjam Ernestus, for valuable comments and criticisms. Part of this paper was presented at the 15th International Congress of Phonetic Sciences, Barcelona, Spain, August 2003.

\section{Appendix A}

The complete set of test sentences. The same sentence frames were used for all test consonants. The main difference was that oma ('grandmother') and opa ('grandfather') were used for female and male names, respectively.

(a) Utterance

Roel ging naar mijn

(1) opa. Tácitus de Vries was gisteren jarig.

(2) oma. Tamára

(5) opa. Sálomon

(3) opa. Dániel

(6) oma. Salóma

(4) oma. Daníla

(7) oma. Zára

(8) opa. Zadók

Roel went to my grandpa (grandma). It was [first name] de Vries' birthday yesterday.

(b) Vocative

Zeg eens de Vries is net aangekomen.

(1) opa, Tácitus

(5) opa, Sálomon

(2) oma, Tamára

(6) oma, Salóma

(3) opa, Dániel

(7) oma, Zára

(4) oma, Daníla

(8) opa, Zadók

Say, grandpa (grandma), [first name] de Vries has just arrived.

(c) List

Vandaag gingen mijn

(1) opa, Tácitus de Vries en Zara de trap af.

(2) oma, Tamára

(5) opa, Sálomon

(3) opa, Dániel

(6) oma, Salóma

(4) oma, Daníla

(7) oma, Zára

(8) opa, Zadók

Today, my grandpa (grandma), [first name] de Vries and Zara went down the stairs.

(Note that the third listed item in the sentence (e.g., 'Zara') also varied among 'Zara', 'Sema', 'Zeno', 'Baba' and 'Nathan'.)

(d) Phonological

Dan gaat mijn de Vries helpen inpakken.

Phrase
(1) opa Tácitus
(5) opa Sálomon
(2) oma Tamára
(6) oma Salóma
(3) opa Dániel
(7) oma Zára
(4) oma Daníla
(8) opa Zadók

Then my grandpa (grandma) is going to help [first name] de Vries to pack. 
(e) Prosodic Word Vanmorgen ging de Vries de trap af.
(1) opa Tácitus
(5) opa Sálomon
(2) oma Tamára
(6) oma Salóma
(3) opa Dániel
(7) oma Zára
(4) oma Daníla
(8) opa Zadók

This morning, grandpa (grandma) [first name] de Vries went down the stairs.

\section{Appendix B}

(A) Distributions of test sentence types (Utterance, Vocative, List, Phonological Phrase (PhP), Prosodic Word (PrWd) in each prosodic category: Big Phrase (BG), Small Phrase (SM) and Prosodic Word (WD)). (Numbers in parentheses indicate the number of tokens observed.)

$\begin{array}{llccccc}\text { Prosodic categories } & \text { Sentence types } & / \mathrm{t} /(\%) & / \mathrm{d} /(\%) & / \mathrm{s} /(\%) & / \mathrm{z} /(\%) & \text { Total }(\%) \\ \text { BG (boundary tone } & \text { Utterance } & 47(128) & 42(132) & 44(131) & 44(130) & 44.3(521) \\ \text { and pause) } & \text { Vocative } & 38(102) & 38(117) & 38(113) & 40(120) & 38.4(452) \\ & \text { List } & 12(33) & 15(46) & 16(48) & 12(37) & 13.9(164) \\ & \text { PhP } & 3(8) & 5(16) & 1(4) & 4(11) & 3.3(39) \\ & \text { PrWd } & 0(0) & 0(0) & 0(0) & 0(0) & 0(0) \\ & \text { Total } & 100(271) & 100(311) & 100(296) & 100(298) & 100(1176) \\ \text { SM (boundary tone } & \text { Utterance } & 2(4) & 0(0) & 0(1) & 1(2) & 0.8(7) \\ \text { and no pause) } & \text { Vocative } & 12(30) & 7(15) & 9(19) & 5(12) & 8.3(76) \\ & \text { List } & 39(99) & 40(86) & 38(84) & 41(95) & 39.6(364) \\ & \text { PhP } & 47(121) & 53(113) & 53(117) & 52(120) & 51.3(471) \\ & \text { PrWd } & 0.3(1) & 0(0) & 0(0) & 0(0) & 0.1(1) \\ & \text { Total } & 100(255) & 100(214) & 100(221) & 100(229) & 100(919) \\ \text { WD (no boundary } & \text { Utterance } & 0(0) & 0(0) & 0(0) & 0(0) & 0(0) \\ \text { tone and no pause) } & \text { Vocative } & 0(0) & 0(0) & 0(0) & 0(0) & 0(0.0) \\ & \text { List } & 0(0) & 0(0) & 0(0) & 0(0) & 0(0.0) \\ & \text { PhP } & 2(3) & 2(3) & 8(11) & 1(1) & 3.3(18) \\ & \text { PrWd } & 98(131) & 98(132) & 92(132) & 99(132) & 96.7(527) \\ & \text { Total } & 100(134) & 100(135) & 100(143) & 100(133) & 100(545)\end{array}$

(B) Distributions of the prosodic categories (Big Phrase (BG), Small Phrase (SM) and Prosodic Word (WD)) within each sentence type (Utterance, Vocative, List, Phonological Phrase, Prosodic Word).

\begin{tabular}{llrrrrr} 
Sentence types & $\begin{array}{l}\text { Prosodic } \\
\text { categories }\end{array}$ & $/ \mathrm{t} /(\%)$ & $/ \mathrm{d} /(\%)$ & $/ \mathrm{s} /(\%)$ & $/ \mathrm{z} /(\%)$ & Mean $(\%)$ \\
\multirow{3}{*}{ Utterance } & $\mathrm{BG}$ & 97.0 & 100.0 & 99.2 & 98.5 & 98.7 \\
& $\mathrm{SM}$ & 3.0 & 0.0 & 0.8 & 1.5 & 1.3 \\
& WD & 0.0 & 0.0 & 0.0 & 0.0 & 0.0
\end{tabular}




\begin{tabular}{llrrrrr} 
Vocative & BG & 77.3 & 88.6 & 85.6 & 90.9 & 85.6 \\
& SM & 22.7 & 11.4 & 14.4 & 9.1 & 14.4 \\
\multirow{3}{*}{ List } & WD & 0.0 & 0.0 & 0.0 & 0.0 & 0.0 \\
& BG & 25.0 & 35.6 & 36.4 & 28.0 & 31.3 \\
& SM & 75.0 & 64.4 & 63.6 & 72.0 & 68.8 \\
\multirow{2}{*}{ Phonological } & WD & 0.0 & 0.0 & 0.0 & 0.0 & 0.0 \\
Phrase & BG & 5.3 & 12.1 & 3.0 & 9.1 & 7.4 \\
& SM & 91.7 & 85.6 & 88.6 & 90.9 & 89.2 \\
\multirow{2}{*}{ Prosodic Word } & WD & 3.0 & 2.3 & 8.3 & 0.0 & 3.4 \\
& BG & 0.0 & 0.0 & 0.0 & 0.0 & 0.0 \\
& SM & 0.8 & 0.0 & 0.0 & 0.0 & 0.2 \\
& WD & 99.2 & 100.0 & 100.0 & 100.0 & 99.8
\end{tabular}

\section{References}

van Alphen, P. M, \& Smits, R. (2004). Acoustical and perceptual analysis of the voicing distinction in Dutch initial plosives: The role of prevoicing. Journal of Phonetics, 32, 455-491.

Baayen, R. H., Piepenbrock, R., \& van Rijn, H. (1993). The CELEX lexical database (CD-ROM). Philadelphia: Linguistic Data Consortium.

Beckman, M. E. (1986). Stress and non-stress accent. Dordrecht: Foris Publications.

Beckman, M. E., \& Edwards, J. (1994). Articulatory evidence for differentiating stress categories. In P. A. Keating (Ed.), Papers in laboratory phonology III: Phonological structure and phonetic form (pp. 7-33). Cambridge: Cambridge University Press.

Beckman, M. E. \& Elam, G. A. (1997). Guidelines for ToBI labelling, Version 3.0. Unpublished Manuscript, Ohio State University.

Beckman, M. E., \& Pierrehumbert, J. (1986). Intonational structure in Japanese and English. Phonology Yearbook, 3, 255-309.

Booij, G. (1995). The phonology of Dutch. Oxford: Clarendon Press.

Byrd, D. (2000). Articulatory vowel lengthening and coordination at phrasal junctures. Phonetica, 57, 3-16.

Byrd, D., Kaun, A., Narayanan, S., \& Saltzman, E. (2000). Phrasal signatures in articulation. In M. Broe, \& J. Pierrehumbert (Eds.), Acquisition and the lexicon: Papers in laboratory phonology V (pp. 70-88). Cambridge, UK: Cambridge University Press.

Byrd, D., \& Saltzman, E. (2003). The elastic phrase: Modeling the dynamics of boundary-adjacent lengthening. Journal of Phonetics, 31, 149-180.

Cambier-Langeveld, T. (1999). The interaction between final lengthening and accentual lengthening: Dutch versus English. In Proceedings of the 14th international congress of phonetic sciences (Vol. 1, pp. 467-470).

Cambier-Langeveld, T. (2000). Temporal marking of accent and boundaries. Ph.D. dissertation, University of Amsterdam (LOT Series 32).

Cambier-Langeveld, T., Nespor, M., \& van Heuven, V. J. (1997). The domain of final lengthening in production and perception in Dutch. In Proceedings of Eurospeech '97 (Vol. 2, pp. 931-934).

Cambier-Langeveld, T., \& Turk, A. (1999). A cross-linguistic study of accentual lengthening: Dutch vs. English. Journal of Phonetics, 27, 255-280.

Carlson, K., Clifton, C., Jr., \& Frazier, L. (2001). Prosodic boundaries in adjunct attachment. Journal of Memory and Language, $45,58-81$. 
Cho, T. (2002). The effects of prosody on articulation in English. New York: Routledge.

Cho, T. (2004). Prosodically conditioned strengthening and vowel-to-vowel coarticulation in English. Journal of Phonetics, 32, 141-176.

Cho, T. (in press). Manifestation of prosodic structure in articulation: evidence from lip kinematics in English. In L. M. Goldstein, D. H. Whalen, \& C. T. Best (Eds.), Laboratory phonology 8: Varieties of phonological competence. Berlin/ New York: Mouton de Gruyter.

Cho, T. (2005). Prosodic strengthening and featural enhancement: evidence from acoustic and articulatory realizations of /a,i/ in English. Journal of the Acoustical Society of America, 117(6), 3867-3878.

Cho, T., \& Jun, S. (2000). Domain-initial strengthening as featural enhancement: Aerodynamic evidence from Korean. Chicago Linguistics Society, 36, 31-44.

Cho, T., Jun, S.-A., \& Ladefoged, P. (2002). Acoustic and aerodynamic correlates of Korean stops and fricatives. Journal of Phonetics, 30, 193-228.

Cho, T., \& Keating, P. (2001). Articulatory and acoustic studies of domain-initial strengthening in Korean. Journal of Phonetics, 29, 155-190.

Cho, T., \& Ladefoged, P. (1999). Variation and universals in VOT: Evidence from 18 languages. Journal of Phonetics, 27, 207-229.

Cho, T., McQueen, J. M., \& Cox, E. (submitted). Prosodically driven phonetic detail in speech processing: the case of domain-initial strengthening in English. Journal of Phonetics.

Choi, H. (2003). Prosody-induced acoustic variation in English stop consonants. In Proceedings of the 15th international congress of phonetic sciences, Barcelona, Spain, 2003.

Cohn, A. (1993). Nasalization in English: Phonology or phonetics. Phonology, 10, 43-81.

Cole, J., Choi, H., Kim, H., \& Hasegawa-Johnson, M. (2003). The effect of accent on the acoustic cues to stop voicing in Radio News speech. In Proceedings of the 15th international congress of phonetic sciences, Barcelona, Spain, 2003.

Collier, R., \& 't Hart, J. (1981). Cursus Nederlands intonatie ['A Course for Dutch Intonation']. Leuven: Acco.

Cooper, A. (1991). Glottal gestures and aspiration in English. Ph.D. dissertation, Yale University.

Cutler, A. (2001). Prosody. In P. Winn (Ed.), Dictionary of biological psychology (p. 633). London: Routledge.

De Jong, K. (1995). The supraglottal articulation of prominence in English: Linguistic stress as localized hyperarticulation. Journal of the Acoustical Society of America, 97, 491-504.

De Jong, K., Beckman, M. E., \& Edwards, J. (1993). The interplay between prosodic structure and coarticulation. Language and Speech, 36, 197-212.

De Jong, K., \& Zawaydeh, B. (2002). Camparing stress, lexical focus, and segmental focus: Patterns of variation in Arabic vowel duration. Journal of Phonetics, 30, 53-75.

De Pijper, J. R., \& Sanderman, A. (1994). On the perceptual strength of prosodic boundaries and its relation to suprasegmental cues. Journal of the Acoustical Society of America, 96, 2037-2047.

Edwards, J. E., Beckman, M. E., \& Fletcher, J. (1991). The articulatory kinematics of final lengthening. Journal of the Acoustical Society of America, 89, 369-382.

Eefting, W. (1991). The effect of "information value" and "accentuation" on the duration of Dutch words, syllables, and segments. Journal of the Acoustical Society of America, 89, 412-424.

Ernestus, M. (2000). Voice assimilation and segment reduction in casual Dutch: a corpus-based study of the phonology-phonetics interface. Ph.D. dissertation, Vrije Universiteit, Amsterdam (LOT Series 36).

Forrest, K., Weismer, G., Milenkovic, P., \& Dougall, R. N. (1988). Statistical analysis of word-initial voiceless obstruents: Preliminary data. Journal of the Acoustical Society of America, 84, 115-123.

Fougeron, C. (1999). Prosodically conditioned articulatory variations: A review. UCLA Working Papers in Phonetics, 97, 1-74.

Fougeron, C. (2001). Articulatory properties of initial segments in several prosodic constituents in French. Journal of Phonetics, 29, 109-135.

Fougeron, C., \& Keating, P. A. (1997). Articulatory strengthening at edges of prosodic domains. Journal of the Acoustical Society of America, 106, 3728-3740.

Gussenhoven, C. (1988). Adequacy in intonation analysis: The case of Dutch. In H. Van der Hulst, \& N. Smith (Eds.), Autosegmental studies on pitch accent (pp. 95-121). Dordrecht: Foris. 
Gussenhoven, C. (2004). A vowel height split explained: compensatory listening and speaker control. Talk presented at the ninth conference on laboratory phonology. University of Illinois at Urbana-Champaign, June 24-June 26, 2004.

Gussenhoven, C. \& Driessen, W. (2004). Explaining two correlations between vowel quality and tone: the duration connection. In Proceedings of the speech prosody 2004 (pp. 179-182). Nara, Japan (also available form: http:// www.isca-speech.org/archive/sp2004/sp04_179.pdf).

Gussenhoven, G., Rietveld, T., \& Terken, J. (1999). ToDI: transcription of Dutch intonation, Version 1.1. University of Nijmegen (http://lands.let.kun.nl/todi/todi/home.htm).

Hacopian, N. (2003). A three-way VOT contrast in final position: Data from Armenian. Journal of the International Phonetic Association, 33, 51-80.

Halle, M. \& Stevens, K. (1971). A note on laryngeal features. Quarterly Progress Report, 101, 198-212. Cambridge, MA: Research Laboratory of Electronics, MIT.

't Hart, J., Collier, R., \& Cohen, A. (1990). A perceptual study of intonation. Cambridge: Cambridge University Press.

Harrington, J., \& Cassidy, S. (1999). Techniques in speech acoustics. Dordrecht: Kluwer Academic Publishers.

Harrington, J., Fletcher, J., \& Roberts, C. (1995). Coarticulation and the accented/unaccented distinction: Evidence from jaw movement data. Journal of Phonetics, 23, 305-322.

Hayashi, W., Hsu, C., \& Keating, P. (1999). Domain-initial strengthening in Taiwanese: A follow-up study. UCLA Working Papers in Phonetics, 97, 152-156.

Hayes, B. (1989). The prosodic hierarchy in meter. In P. Kiparsky, \& G. Youmans (Eds.), Phonetics and phonology: Rhythm and meter, Vol. I (pp. 47-96). New York: Academic Press.

Hays, W. L. (1994). Statistics (5th ed.). New York: Harcourt Brace College Publishers.

Hofhuis, E., Gussenhoven, C., \& Rietveld, A. (1995). Final lengthening at prosodic boundaries in Dutch. In Proceedings of the 13th international congress of phonetic sciences (pp. 154-157). Stockholm, 1995.

Hsu, C.-S., \& Jun, S.-A. (1998). Prosodic strengthening in Taiwanese: Syntagmatic or paradigmatic? UCLA Working Papers in Phonetics, 96, 69-89.

Huynh, H., \& Feldt, L. S. (1970). Conditions under which mean square ratios in repeated measurements designs have exact F-distributions. Journal of the American Statistical Association, 65, 1582-1589.

Jun, S.-A. (1993). The phonetics and phonology of Korean prosody. Ph.D. dissertation, Ohio State University.

Jun, S.-A. (1995). Asymmetrical prosodic effects on the laryngeal gesture in Korean. In B. Connell, \& A. Arvaniti (Eds.), Phonology and phonetic evidence: Papers in laboratory phonology IV (pp. 235-253). Cambridge, UK: Cambridge University Press.

Jun, S.-A. (2003). Prosodic phrasing and attachment preferences. Journal of Psycholinguistic Research, 32, $219-249$.

Keating, P. A. (1984a). Phonetic and phonological representation of stop consonant voicing. Language, 60, 286-319.

Keating, P. A. (1984b). Physiological effects on stop consonant voicing. UCLA Working Papers in Phonetics, 59, 29-34.

Keating, P. A. (1990). Phonetic representations in a generative grammar. Journal of Phonetics, 18, 321-334.

Keating, P. A., Cho, T., Fougeron, C., \& Hsu, C. (2003). Domain-initial strengthening in four languages. In J. Local, R. Ogden, \& R. Temple (Eds.), Papers in laboratory phonology 6: Phonetic interpretations (pp. 145-163). Cambridge, UK: Cambridge University Press.

Keating, P. A., \& Shattuck-Hufnagel, S. (2003). A prosodic view of word form encoding for speech production. UCLA Working Papers in Phonetics, 101, 112-156.

Kim, S. (2001). The interaction between prosodic domain and segmental properties: Domain-initial strengthening of Korean fricatives and Korean post-obstruent tensing rule. Unpublished M.A. thesis, University of California, Los Angeles.

Kim, S. (2003). The role of post-lexical tonal contours in word segmentation. In Proceedings of the 15th international congress of phonetic sciences, Barcelona, Spain, 2003.

Kim, S. (2004a). The role of prosodic phrasing in Korean word segmentation. Unpublished Ph.D. dissertation, University of California, Los Angeles.

Kim, S. (2004b). The role of prosodic cues in word segmentation of Korean. In Proceedings of the eighth international conference on spoken language processing, Interspeech 2004, Jeju, Korea, 2004.

Kim, S. (in press). Domain-initial strengthening of Korean fricatives. Harvard Studies in Korean Linguistics, IX.

Kingston, J., \& Diehl, R. L. (1994). Phonetic knowledge. Language, 70, 419-454. 
Kirk, R. E. (1995). Experimental design: Procedures for the behavioral sciences. Pacific Grove, CA: Brooks/Cole Publishing Company.

Kjelgaard, M. M., \& Speer, S. R. (1999). Prosodic facilitation and inference in the resolution of temporal syntactic closure ambiguity. Journal of Memory and Language, 40, 153-194.

Klatt, D. (1976). Linguistic uses of segmental duration in English: Acoustic and perceptual evidence. Journal of the Acoustical Society of America, 59, 1208-1221.

Krakow, R. A. (1999). Physiological organization of syllables: A review. Journal of Phonetics, 27, $23-54$.

Ladefoged, P., \& Cho, T. (2001). Linguistic contrasts to reality: The case of VOT. In N. Grønnum, \& J. Rischel (Eds.), Travaux Du Cercle Linguistique De Copenhague, Vol. XXXI (pp. 212-225). Copenhagen: C.A. Reitzel.

Lehiste, I. (1970). Suprasegmentals. Cambridge, MA: MIT Press.

Liberman, M., \& Prince, A. (1977). On stress and linguistic rhythm. Linguistic Inquiry, 8, 29-336.

Liljencrants, J., \& Lindblom, B. (1972). Numerical simulation of vowel quality systems: The role of perceptual contrast. Language, 48, 839-862.

Lindblom, B. (1986). Phonetic universals in vowel systems. In J. Ohala, \& J. Jaeger (Eds.), Experimental phonology (pp. 13-44). Orlando: Academic Press.

Lindblom, B. (1990). Explaining phonetic variation: A sketch of the H \& H theory. In W. J. Hardcastle, \& Marchal (Eds.), Speech production and speech modeling (pp. 403-440). Dordrecht: Kluwer Academic Publishers.

Lisker, L., \& Abramson, A. (1964). A cross-language study of voicing in initial stops: Acoustical measurements. Word, $20,384-422$.

Lisker, L., \& Abramson, A. (1967). Some effects of context on voice onset time in English stops. Language and Speech, $10,1-28$.

Marsi, E. (2001). Intonation in spoken language generation. Ph.D. dissertation, University of Nijmegen (LOT Series 46).

Max, L., \& Onghena, P. (1999). Some issues in the statistical analysis of completely randomized and repeated measures designs for speech, language, and hearing research. Journal of Speech, Language, and Hearing Research, 42, 261-270.

McQueen, J. M. \& Cho, T. (2003). The use of domain-initial strengthening in segmentation of continuous English speech. In Proceedings of the 15th international congress of phonetic sciences, Barcelona, Spain, 2003.

Nespor, M., \& Vogel, I. (1986). Prosodic phonology. Dordrecht: Foris.

Nooteboom, S. G. (1972). Production and perception of vowel duration. A study of durational properties of vowels in Dutch. Ph.D. dissertation, University of Utrecht.

Ohala, J. (1983). The origin of sound patterns in vocal tract constraints. In P. F. MacNeilage (Ed.), The production of speech (pp. 189-216). New York: Springer.

Onaka, A., Palethorpe, S., Watson, C., \& Harrington, J. (2002). Acoustic and articulatory difference of speech segments at different prosodic positions. In Proceedings of the ninth Australian international conference on speech science and technology (pp. 148-153).

Pierrehumbert, J., \& Talkin, D. (1992). Lenition of /h/ and glottal stop. In G. Docherty, \& D. R. Ladd (Eds.), Papers in laboratory phonology II: Gesture, segment, prosody (pp. 90-117). Cambridge, UK: Cambridge University Press.

Salverda, A. P., Dahan, D., \& McQueen, J. M. (2003). The role of prosodic boundaries in the resolution of lexical embedding in speech comprehension. Cognition, 90, 51-89.

Schafer, A. (1997). Prosodic Parsing: The Role of Prosody in Sentence Comprehension. Ph.D. dissertation, University of Massachusetts, Amherst.

Selkirk, E. (1984). Phonology and syntax: The relation between sound and structure. Cambridge, MA: MIT Press.

Selkirk, E. (1986). On derived domains in sentence phonology. Phonology Yearbook, 3, 371-405.

Shattuck-Hufnagel, S., \& Turk, A. E. (1996). A prosody tutorial for investigators of auditory sentence processing. Journal of Psycholinguistic Research, 25, 193-247.

Sheskin, D. J. (2000). Handbook of parametric and nonparametric statistical procedures (2nd ed.). Boca Raton: Chapman \& Hall/CRC.

Silverman, K., Beckman, M., Pitrelli, J., Ostendorf, M., Wightman, C., Price, P., Pierrehumbert, J., \& Hirschberg, J. (1992). TOBI: a standard for labeling English prosody. In Proceedings of the 1992 international conference on spoken language processing (Vol. 2, pp. 867-870).

Sluiter, A. (1995). Phonetic correlates of stress and accent. Ph.D. dissertation, Leiden University.

Stevens, K. N. (1999). Acoustic phonetics. Cambridge, MA: MIT Press. 
Stevens, K. N., Keyser, S. J., \& Kawasaki, H. (1986). Toward a phonetic and phonological theory of redundant features. In J. S. Perkell, \& D. H. Klatt (Eds.), Invariance and variability in speech processes (pp. 426-463). Hillsdale, NJ: Lawrence Erlbaum Associates.

Tabain, M. (2003a). Effects of prosodic boundary on /aC/ sequences: Acoustic results. Journal of the Acoustical Society of America, 113, 516-531.

Tabain, M. (2003b). Effects of prosodic boundary on $/ \mathrm{aC} /$ sequences: Articulatory results. Journal of the Acoustical Society of America, 113, 2834-2849.

Turk, A., \& Sawusch, J. (1997). The domain of accentual lengthening in English. Journal of Phonetics, 25, $25-41$.

Turk, A. E., \& Shattuck-Hufnagel, S. (2000). Word-boundary-related durational patterns in English. Journal of Phonetics, 28, 397-440.

Turk, A., \& White, L. (1999). Structural influences on accentual lengthening in English. Journal of Phonetics, 27, $171-206$.

Westbury, J. R. (1983). Enlargement of the supraglottal cavity and its relation to stop consonant voicing. Journal of the Acoustical Society of America, 73, 1322-1336.

Westbury, J. R., \& Keating, P. A. (1986). On the naturalness of stop consonant voicing. Journal of Linguistics, 22, $145-166$

Wightman, C. W., Shattuck-Hufnagel, S., Ostendorf, M., \& Price, P. J. (1992). Segmental durations in the vicinity of prosodic phrase boundaries. Journal of the Acoustical Society of America, 91, 1707-1717.

Zsiga, E. (1993). Features, gestures and the temporal aspects of phonological organization. Ph.D. dissertation, Yale University. 